\title{
The Trend is Your Friend: Time-series Momentum Strategies across Equity and Commodity Markets
}

\author{
Athina Georgopoulou, Jiaguo (George) Wang \\ This revision: May 2016 \\ Forthcoming at the Review of Finance
}

\begin{abstract}
This paper documents a significant time-series momentum effect that is consistent and robust across all examined conventional asset classes from 1969 to 2015. We find that the duration and magnitude of time-series momentum is different in developed and emerging markets, but this is no longer the case when controlling for the currency component. We further demonstrate that time-series momentum captures a significant proportion of international mutual fund performance, but this is predominantly with respect to its long aspect. Finally, the market interventions by central banks in recent years have distorted correlations across assets; this challenges the performance of such portfolios.
\end{abstract}

JEL classification: G12, G13, G15, G23, G11

Keywords: Return Predictability, Momentum, International Mutual Funds, Market Efficiency, International Financial Markets

\footnotetext{
${ }^{*}$ Georgopoulou is with SEI Investments London Office and Wang is with Manchester Business School. Contact email George.wang@manchester.ac.uk. We would like to thank Bernard Dumas (the Editor), two anonymous referees, Mike Bowe, Ian Garett and Spencer Martin for helpful comments. Part of this version was completed while George was a visiting research professor at NYU Stern, and he would like to thank the host Stephen Brown and the people there for their hospitality and helpful comments.
} 
"Over time, value is roughly the way the market prices stocks, but over the short term, which sometimes can be as long as two or three years, there are periods when it doesn't work. And that is a very good thing."

— Jack D. Schwager

\section{Introduction}

The momentum anomaly can be encountered in two dimensions: cross-sectional and time-series. According to the traditional and well-documented idea of cross-sectional momentum, instruments that outperform their peers in a three- to twelve-month period tend to do so also over the next year. ${ }^{2}$ A newer version of the momentum anomaly refers to timeseries momentum, which focuses on an instrument's absolute performance. In particular, according to the time-series momentum perspective, an asset's past performance predicts its future performance, emphasizing the crucial role of autocorrelation in returns. Moskowitz, Ooi, and Pedersen (2012) are the first to provide evidence of the existence of time-series momentum with respect to futures markets. They find that excess return during the preceding 12-month period of a futures contract is a positive predictor of its future return during the next year and that a diversified portfolio that buys instruments that have been in an uptrend and sells those that have been in a downtrend delivers substantial abnormal returns. ${ }^{3}$

Recent studies on time-series momentum have focused primarily on futures markets and managed futures funds (e.g., Baltas and Kosowski, 2013; Moskowitz et al., 2012). Given that more than 9.5 trillion U.S. dollars in assets are estimated to have been benchmarked to global equity (i.e., MSCI indexes) and commodity indexes (i.e., S\&P GSCI) by the end of 2014 and that there is an increasing number of international mutual funds and exchange traded funds (ETFs), academic research has devoted surprisingly little attention to trend following and time-series momentum effects among conventional asset classes. ${ }^{4}$

Our paper makes three major contributions to the existing literature. First, this study is among the first to examine the relevance and effectiveness of time-series momentum in

\footnotetext{
${ }^{2}$ Extensive studies have provided evidence of the cross-sectional momentum profitability for several decades (e.g., Jegadeesh and Titman, 1993; Asness, 1994; Grundy and Martin, 2001; Griffin, Ji, and Martin, 2003; Yao 2012); and across various asset classes and countries (e.g., Asness, Liew, and Stevens, 1997; Rouwenhorst, 1998; Moskowitz and Grinblatt, 1999; Bhojraj and Swaminathan, 2006; Erb and Harvey, 2006; Gorton, Hayashi, and Rouwenhorst, 2008; Garleanu and Pedersen, 2009; DeMiguel, Nogales, and Uppal, 2010; and Asness, Moskowitz and Pedersen, 2013).

${ }^{3}$ Baltas and Kosowski (2013) confirm the profitability of time-series momentum strategies in global futures markets, and they further show that time-series momentum strategies explain a significant part of hedge fund returns. Menkhoff et al. (2012), however, find that cross-sectional momentum outperforms time-series in the currency market.

${ }^{4}$ MSCI stands for Morgan Stanley Capital Indexes. GSCI stands for Goldman Sachs Commodity Indexes. The actual figures are available at www.msci.com/indexes.
} 
conventional asset classes. ${ }^{5}$ In particular, we find the nature of time-series momentum strategies is different in developed and emerging markets. For instance, emerging markets experience much higher time-series momentum returns compared to developed markets. The time-series momentum phenomenon, however, is of a shorter duration in emerging markets, and the profitability of such strategies starts to dissipate much more quickly than in developed markets. To shed some light on this fundamental difference, we apply time-series strategies in developed and emerging markets by examining both their USD and local returns. ${ }^{6}$ Remarkably, we find that the profits in emerging markets are no longer short-term in nature once we control for the currency component. Instead, the lasting effect of time-series momentum appears overall very similar for both markets. We further investigate the return continuation pattern in the currency component of the developed and emerging market equity indices, and we find the magnitude of this pattern is larger for emerging markets than for developed ones, especially in the short term. ${ }^{7}$ Therefore, the difference in the currency return continuation patterns largely explains the different time-series momentum profitability for emerging and developed markets.

A second major contribution of our work is to directly link time-series momentum to the performance of international mutual funds. We accordingly provide a new benchmark to evaluate international fund performance. Over the years, trend-following strategies have become one of the most important investment strategies in the hedge fund universe. For instance, Moskowitz et al. (2012), Baltas and Kosowski (2013), and Hurst, Ooi, and Pedersen (2014) document that a substantial part of the hedge fund industry, such as managed futures funds and commodity trading advisors (CTAs), follows time-series momentum strategies. We extend this line of research by examining whether particular strategies can be associated with other types of institutional investors, i.e., international mutual funds, which can be characterized as more traditional and risk-averse, or whether they strictly concern the hedge fund industry.

We find that the time-series momentum trading strategy explains a significant proportion of international mutual fund performance, but mainly with respect to its long-only

\footnotetext{
${ }^{5}$ We thank an anonymous referee suggesting that the differences between cash and future market momentum could be due to the role of the futures roll return and the difference between using cash equity indices and futures. We do not further illustrate the difference between future and current market as it is not the main focus of the current paper. Our main interest is on traditional asset classes rather than futures market which have been comprehensively investigated in recent literature (e.g. Moskowitz et al., 2012; Baltas and Kosowski, 2013).

${ }^{6}$ We thank an anonymous referee for motivating relevant tests. Here our findings are also consistent with the currency momentum findings in Menkhoff et al. (2012).

${ }^{7}$ Our findings are consistent with the currency momentum strategies proposed by Menkhoff et al. (2012). We do not further investigate currency momentum since it is not the focus of this paper.
} 
aspect. ${ }^{8}$ Specifically, international mutual funds have proven to be long-only time-series momentum investors, implying that they tend to buy instruments that have been in an uptrend, but they do not sell those that have been in a downtrend. Indeed, a long-only portfolio that invests in instruments that have been performing well or that are in risk-free assets almost entirely captures mutual fund behavior. Therefore, it is likely that mutual funds will show an investment preference for long-only trend-following strategies. These findings are consistent and robust across all samples of asset classes and mutual funds examined. Moreover, they complement existing literature on cross-sectional momentum (e.g., Grinblatt, Titman, Wermers, 1995; Breloer, Scholz and Wilkens, 2014), where there is evidence that mutual funds have a tendency to buy winners but do not systematically sell losers.

The third major contribution of our work is to show that, the market interventions by central banks in recent years challenge the performance of time-series momentum portfolios. Importantly, the addition of more recent data permits an investigation of time-series momentum in light of central bank intervention, which is known to have distorted correlations across asset classes (Baltas and Kosowski, 2013, 2015). ${ }^{9}$ To underpin our argument, we first examine the correlations across all equity and commodity indices with respect to three crucial periods: pre-QE (Quantitative Easing), at-QE, and post-QE. We find that the examined assets are much more highly correlated in the pre-QE period than in the atQE period, with correlations spiking in 98\% of the observations. We then examine the same relation between the at-QE period and the post-QE period, and, interestingly, we find that correlations have been normalizing back towards their previous pre-crisis levels. To further strengthen our argument, we perform regression tests to investigate whether there is indeed any relation between our strategy and the money printing policy adopted by the Federal Reserve Bank. Indeed, we find significant negative impacts of QE on time-series momentum profitability. It is also interesting that the impact is not particularly strong for the commodity indices that we examine, implying that their inclusion in the momentum strategy is highly diversifying.

These findings suggest that time-series momentum has been threatened in recent years by the aggressive policy employed by central banks and that restoring correlations across assets to their normal pre-crisis levels may play a crucial role in recovering time-series

\footnotetext{
${ }^{8}$ For example, Cumby and Glen (1990) examine the risk-adjusted performance of international mutual funds, while Goetzmann, Ivkovic, and Rowenhourst (2001) and Chua, Lai, and Wu (2008) investigate their fair pricing.

${ }_{9}^{9}$ For comprehensive strategies on how to improve performance under such situations, please refer to Baltas and Kosowski (2015).
} 
momentum attractiveness. It would be also interesting to examine the behavior of time-series momentum as we move further ahead from the end of the QE era. Another important paper in the field is that of Baltas and Kosowski (2015), who demonstrate that weighting schemes which incorporate correlation could improve the net of transaction costs performance during the post global financial crisis period. The effect of monetary policy on such a diverse set of assets, such as global equity and commodity assets, calls for comprehensive theoretical and empirical research, including a clearly spelled out economic transmission mechanism. ${ }^{10}$

Moreover, we find that a diversified long-short time-series momentum portfolio realizes its largest profits in extreme market conditions. ${ }^{11}$ Specifically, we find that timeseries momentum serves as a hedging strategy in all conventional asset classes examined and that its payoffs resemble those of an option straddle, which is consistent with Moskowitz et al. (2012). Time-series momentum experiences its highest gains during extreme markets. To enhance our understanding further, we also examine a less volatile short-term time-series momentum strategy and find that not only does it perform better throughout the period, but it also serves as a better hedging tool than the longer-term one. ${ }^{12}$ These results suggest that the time-series momentum profitability is more likely to be a function of its look-back period and the established trend at that point.

The rest of this paper is organized as follows. Section 2 reviews the related literature. Section 3 describes the dataset and the methodology used for constructing momentum strategies. Section 4 presents the results of time-series momentum trading strategies, while Section 5 presents evidence that international mutual fund performance is closely related to time-series momentum trading strategies. Section 6 investigates time-series momentum profitability during extreme market conditions and the role of central banks. Section 7 presents our conclusions.

\section{Related Literature}

\subsection{Evidence for Time-Series Momentum}

In 2012, Moskowitz, Ooi, and Pedersen provided alternative evidence to the momentum phenomenon, focusing on what they called time-series momentum. They describe time-series momentum as an asset-pricing anomaly in which an instrument's past return is

\footnotetext{
${ }^{10}$ We thank an anonymous referee for suggesting this point.

${ }^{11}$ We thank an anonymous referee for suggesting this point. The exploration of the differences in the magnitude of momentum crashes with respect to the two momentum strategies sheds more light on our findings.

${ }^{12}$ For brevity, the result for shorter term momentum strategies (e.g. 3-1 strategy) is briefly described in footnote 19. Detailed results are available upon request.
} 
positively correlated with its future return over a period of 1 to 12 months. This suggests that one could generate higher returns simply by using long instruments with recent positive returns and going short for those with recent negative returns. Moskowitz et al. (2012) examine this trend-following phenomenon for 58 futures and forward contracts from various asset classes and find that it persists in each of the contracts they study. They also note that returns generated by time-series momentum strategies partially reverse over longer horizons, supporting behavioral explanations of initial under-reaction and delayed over-reaction.

Moskowitz et al. (2012) note that time-series momentum is related to but distinct from the classic cross-sectional momentum of Jegadeesh and Titman (1993). In order to investigate this, they decompose returns into time-series and cross-sectional momentum strategies, and they find that lead-lag effects that contribute to cross-sectional momentum are not apparent in the case of time-series momentum and that returns of futures contracts have a positive auto-covariance in common. Based on this finding, they conclude that time-series momentum can capture some features of cross-sectional momentum.

Interestingly, they also note that superior returns associated with this trend effect are not due to risk compensation since a time-series momentum strategy performs best during extreme markets. As a result, their time-series momentum trading strategies exhibit no relation with risk factors such as HML (the value factor) and SMB (the size factor), but seem to be partially explained by momentum factors, supporting once again a relationship with cross-sectional momentum.

Moskowitz et al. (2012) attempt to establish a relationship between the positions of hedgers and speculators, as well as a relationship between hedge funds returns and timeseries momentum strategies themselves. Notably, they find that speculators and hedgers engage in time-series momentum strategies, permitting the former to profit at the expense of the latter. As far as hedge fund investment behavior is concerned, they find that hedge fund returns can be explained by these trend-following strategies.

\subsection{Time-Series Momentum and the Performance of Managed Futures Funds}

After the work of Moskowitz et al. (2012) was first released, several studies followed, and these focused primarily on the source of profitability generated by managed futures funds and CTAs, which together constitute a substantial part of the hedge fund industry. In particular, Hurst, Ooi, and Pedersen (2012) observe that trend-following strategies such as time-series momentum can explain managed futures’ returns. Remarkably, they demonstrate that, when they control for time-series momentum strategies, excess returns (or alphas) 
cannot be attributed to other long-only benchmarks. In addition, they also highlight the relative importance of the horizon of these strategies as well as the asset classes that may be concerned. They find that most managed futures funds are focused on medium- and longterm trends, due to lower transaction costs, as well as on fixed income due to its higher liquidity.

In another paper, Hurst, Ooi and Pedersen (2014) provide evidence for a whole century of strong performance of time-series momentum strategies, extending the evidence provided by Moskowitz et al. (2012). Moreover, the authors express their concern about the outlook of time-series momentum strategies in light of their recent drawdowns. Specifically, they claim that the current economic environment, with central banks intervening in the market, not only distorts existing trend patterns, but also leads to increased correlations across futures markets. Therefore, the diversification benefit previously afforded to momentum strategies has been substantially reduced since there are fewer independent trend patterns that can be exploited. However, even in this case, the authors state that managed futures funds could benefit from emerging equity and currency markets, which are much more liquid than in the past.

Baltas and Kosowski (2013) are also concerned with the relationship between timeseries momentum strategies in futures markets and CTAs, and once again they provide strong evidence that CTAs follow time-series momentum. In order to better approximate CTA strategies, they examine higher frequencies such as daily and weekly ones, thereby extending the approach of Moskowitz et al. (2012). Interestingly, they document that strategies at different frequencies exhibit low correlations with one another and therefore reflect distinct continuation phenomena. Additionally, they note that CTAs have been performing poorly recently, and they consider capacity constraints as a possible reason for this underperformance. However, their results indicate that there are no significant capacity constraints on momentum strategies, which is consistent with the view that futures markets are liquid, but it renders the reason for the underperformance of CTAs unclear.

\section{Data and Preliminaries}

The present dataset consists of monthly closing prices for 45 equity indices, covering developed and emerging markets, and 22 commodity indices-in total, 67 different instruments-from December 1969 through August 2015. All instrument prices are denominated in U.S. dollars since this study is conducted from a U.S. perspective. In

addition, the dataset includes monthly returns for international, global, and commodity mutual funds, which are examined to establish a link between time-series momentum and 
mutual fund behavior.

\subsection{International Equity Indices}

The dataset for equity indices is obtained from Bloomberg and consists of monthly closing prices for 45 Morgan Stanley Capital International (MSCI) indices across 23 developed and 22 emerging countries. Price data for equity indices date back to December 1969 or later. The MSCI indices considered are free float-adjusted market capitalization weighted indices that replicate the equity market performance of developed and emerging countries (MSCI, 2014). Given that all of the MSCI indices mainly represent large capitalization and liquid stocks, potential biases due to illiquidity and non-synchronous trading are eliminated.

\subsection{Commodity Indices}

The dataset for commodity indices consists of 22 commodity indices, which are obtained from Bloomberg and date back to December 1969. The dataset is based on the Standard and Poor's Goldman Sachs Commodity Index (S\&P GSCI), which is designed to track an unleveraged and long-only investment in commodity futures and is diversified across individual commodity components (S\&P GSCI, 2014). The commodity indices are weighted to account for economic significance and market liquidity. It is important to highlight that when it comes to returns, excess return indices are considered instead of total returns indices to take into account the effects of contango and normal backwardation in these markets.

\section{[Insert Table I here]}

Table I presents some descriptive statistics for all instruments considered in the present dataset with regard to the beginning of the time-series of data: annualized mean, annualized volatility, skewness, and kurtosis. Looking at these quantities of interest, one can observe that there is a substantial variation in the annualized mean returns across assets, with equity indices generating primarily positive returns, while many commodity indices yield negative returns over the sample period.

As far as the annualized volatilities are concerned, many extreme observations that are even higher than $100 \%$ can be noted, especially in emerging and commodity markets. In contrast to Moskowitz et al. (2012) and Baltas and Kosowski (2013), however, volatilities across asset classes and instruments are more homogeneous and have fewer striking differences. This is because the present dataset does not include currency or bond markets. Finally, the dataset demonstrates reasonable levels of skewness and kurtosis. 


\subsection{Time-Series Return Predictability}

Given that time-series momentum strategies are considered trend-following strategies, it is of great importance to detect price continuation patterns before implementing them. Price continuation patterns would signify return predictability, and that would further suggest that a time-series momentum strategy can generate substantial profits. For this purpose and in a fashion similar to that of Moskowitz et al. (2012), the price continuation is examined across all instruments combined, by regressing the excess return ${ }^{13}$, scaled by volatility, for instrument $j$ in month $t$ on its own return lagged $h$ months. Thus, the pooled panel linear regression can be estimated as follows:

$$
x=\frac{r_{t}^{j}}{\sigma_{t}^{j}}=a+\beta_{h} \frac{r_{t-h}^{j}}{\sigma_{t-h}^{j}}+\varepsilon_{t}
$$

where $r_{t}^{j}$ and $\sigma_{t}^{j}$ are the excess return and realized volatility of instrument $j$ in month $t$, and $\sigma_{t-h}^{j} r_{t-h}^{j}$ are the excess return and realized volatility of instrument $j$ in month $t$ lagged $h$ months.

The regression defined in Equation (1) is a pooled panel regression in which all instruments (67 in total) and dates are combined to generate the beta coefficients. The number of lags for each instrument extends to 60 months $(h=1,2, \ldots, 60)$, and thus 60 regressions are estimated. In this regression, the quantity of interest is the $t$-statistic, where a significant $t$-statistic indicates the existence of time-series return predictability. Specifically, a positive $t$-statistic signifies return continuation, whereas a negative $t$-statistic signifies a reversal.

\section{[Insert Figure 1 here]}

Figure 1 presents the $t$-statistics of the beta coefficients with regard to the pooled panel regression for lags $h=1,2, \ldots, 60$. When asset classes are examined at an aggregate level (Panel A), it can be noted that the t-statistics in all of the first 12 lagged months are positive and significant. Over longer horizons (13 to 60 lags), the $t$-statistics deliver lower positive values and, in some cases, significantly negative values. These results indicate the existence of a return continuation for the first year that subsequently gives rise to weaker reversals. As a result, the hypothesis for time-series return predictability can be confirmed. This implies that past returns are able to predict future returns and that trend-following patterns are thereby created.

These findings are consistent with those documented by Moskowitz et al. (2012) and

\footnotetext{
${ }^{13}$ Data on the three-month Treasury bill are obtained from Bloomberg and used to represent the risk-free rate.
} 
Baltas and Kosowski (2013) with respect to return continuations and reversals in futures markets. Nonetheless, in the present case, the return continuation seems to be more persistent given some positive spikes at lags greater than 12. Apart from that, reversals in returns generate weaker signals than those reported by Moskowitz et al. (2012). Baltas and Kosowski (2013) are also unable to show strong reversals over longer horizons, arguing that this result is due to the use of a larger sample in both time-series and cross-sectional dimensions. This rationale can also be inferred from our present study, where the dataset starts in 1969 and consists of 67 instruments.

As far as asset classes are concerned, the return predictability seems to be slightly stronger in the case of equity versus commodity indices. In the case of equity indices, 11 out of 12 lags are positive and significant, whereas only 7 out of 12 lags are positive and significant for commodity indices. Also, the return continuation tends to be more persistent and decays to a smaller extent for equity indices. Hence, it is expected that time-series momentum strategies will be more profitable for equity than for commodity indices. We also observe more pervasive continuation signals for developed than for emerging equity indices, indicating higher time-series profitability for the former.

\subsection{International Equity and Commodity Funds}

Mutual fund data are obtained from the Morningstar Direct database and cover the period from December 1968 through August 2015. The sample contains all international equity funds, along with commodity funds that exist at any time during the period of 1968 to 2015. The data used for international equity funds begin in December 1968, while that for commodity funds begin in April 1997. All the relevant values are reported in U.S. dollars and the oldest share class data is retained in the sample. Our final sample includes 1,177 international equity fund-entities and 106 commodity fund-entities, comprising 154,259 monthly fund data-points. The number of international equity funds increases steadily starting from five funds in 1968 and reaching 1,084 funds in 2015. Commodity investments seem to be less popular, with commodity fund data existing only from 1997 counting only to one at that time and growing to 70 by 2015 .

\section{[Insert Table II here]}

Sample descriptive statistics are presented in Table II. When looking at the total net assets across the various fund categories, we conclude that the highest interest is concentrated in emerging markets since the value of total net assets there is the largest compared to commodity and developed funds. Nonetheless, we recognize that many smaller cap funds can 
be found in developed markets so that our sample might be biased. In unreported results, though, and after excluding small caps from our sample in developed markets, the mean and median of total net assets increase to 911.03 and 925.96 million, respectively, and these figures are still significantly lower than those observed in funds investing in emerging markets. After controlling for the small cap bias, variability of returns also decreases to levels

similar to those in emerging markets. Turnover for commodity funds is much higher compared to developed and emerging market equity funds, while their returns are modest on a relative basis but have higher variability, followed by emerging and then developed international equity funds.

\section{[Insert Figure 2 here]}

In Figure 2 in panels $\mathrm{A}$ and $\mathrm{B}$, we present the geographical distribution for international equity funds and the holdings distribution for commodity funds, respectively. We base our classification on the Morningstar Category, Investment Area and Primary Prospectus Benchmark for the equity funds and on the Morningstar Category and GIFS for the commodity funds. For the international equity funds, we observe that almost $67 \%$ of them invest on a global and well-diversified basis without showing an investment interest in a specific region. The majority of these funds are assigned to a broad benchmark, such as the MSCI World Index, MSCI ACWI Index, and MSCI EAFE, among others. Many funds show a particular interest in individual regions or countries, among which $27 \%$ of the whole sample represent emerging market countries or regions, whereas only 6\% target individual developed countries or areas. As far as the commodity fund holdings are concerned, $81 \%$ of them are well-diversified and are investing in a broad basket of commodities throughout the sample period. Some show a preference for a specific sub-asset class, which seems to concentrate in precious metals followed by agriculture and energy.

\section{Trading Strategies and Empirical Analysis}

\subsection{Time-Series Momentum Strategies}

In Section 3.3, the positive correlation between past returns and future returns suggests the existence of trend-following patterns. Therefore, it is reasonable to construct time-series momentum strategies that take advantage of these patterns and to evaluate their profitability.

Before analyzing the methodology for constructing time-series momentum strategies, it is of great importance to highlight that these strategies can be constructed based on 
different time horizons. Thus, it is essential to define the periods involved in constructing time-series momentum strategies: the look-back or formation period and the holding period. The look-back period $J$ refers to the number of lagged months in which returns are examined to form the momentum portfolio, while the holding period $K$ refers to the number of months that the momentum portfolio is held after it is formed. $K$ and $J$ can vary through time, allowing for different combinations of look-back and holding periods. Therefore, a 12-1 strategy, where 12 indicates the look-back period $J$ and 1 indicates the holding period $K$, refers to a portfolio that is constructed based on the instrument returns over the previous 12 months and is held for one month after its formation.

As in Moskowitz et al. (2012), Baltas and Kosowski (2013), and Hurst et al. (2012), a time-series momentum strategy takes a long (short) position for a single instrument when the sign of its cumulative return over a particular look-back period is positive (negative). The trading sign takes the value 1 if the cumulative return of the asset over the look-back period $J$ is positive and the value -1 if otherwise. The time-series momentum return of each instrument is calculated based on the trading sign and the return over the holding period. Moreover, similarly to Jegadeesh and Titman (1993), one month is skipped between the formation and holding periods to avoid some of the bid-ask spread, price pressure, and lagged reaction effects (Jegadeesh, 1990; Lehmann, 1990). Subsequently, time-series momentum returns are aggregated to form the momentum portfolios as follows:

$$
P_{J}^{K}=\frac{1}{N_{t}} \sum_{i=1}^{N_{t}} \operatorname{signal}_{j}\left(\mathrm{cumr}_{t-J, t}^{j}\right) r_{t, t+K}^{j}
$$

where $N_{t}$ indicates the number of available instruments at time, $t, P_{J}^{K}$ is the return on the time-series momentum portfolio with a look-back period of $J$ months and holding period of $K$ months, signal $_{j}$ takes the value $1(-1)$ if the cumulative return $c u m r_{t-J, t}^{j}$ in month $t$ for instrument $j$ over the past $J$ months is positive (negative), and $r_{t, t+K}^{j}$ is the return with respect to a holding period of $K$ months.

\section{[Insert Table III here]}

Table III depicts the annualized mean returns alongside their Sharpe ratios generated by time-series momentum strategies over a number of look-back and holding periods. Panels $\mathrm{A}, \mathrm{B}$, and $\mathrm{C}$ present these quantities for all asset classes, equity indices, and commodity indices, respectively. The annualized mean returns of time-series momentum strategies are positive and statistically different from zero with respect to time horizons of up to one year. Over longer horizons, time-series momentum strategies deliver lower returns that are either 
not significant or negative (for commodity indices, Panel C). These findings confirm the price continuation patterns detected in the previous section and the results documented in the time-series momentum literature. It can therefore be concluded that, apart from the case of futures markets, time-series momentum can successfully be applied to a more traditional range of instruments, such as equity and commodity indices. Moreover, the particular strategies seem to yield a respectable 0.77 Sharpe ratio when applied for up to one year. Time-series momentum strategies can also successfully be applied to individual stocks. Further investigation of individual stocks, however, is beyond the scope of this study.

Taking a closer look at panels B and C, where each asset class is examined separately, one can observe that time-series momentum profitability is slightly more pronounced across equity indices than commodity indices. More precisely, time-series momentum delivers annualized returns in the range of $2 \%$ to $15 \%$ with regard to equity markets, and $2 \%$ to $10 \%$ with regard to commodity markets. The higher momentum profitability of equity indices is further supported by noticing their respective Sharpe ratios, which seem superior in equity markets.

These findings confirm the predictability patterns observed in the previous section, where return continuations proved to be stronger for equity indices. Surprisingly, reversal patterns in time-series momentum returns are observed only for commodity indices, while with equity indices, only weaker positive returns are noted. This might also be the reason why, when the aggregate strategy is examined, similar behavior can be observed. Once again, these findings are in line with those reported by Baltas and Kosowski (2013), who could not find strong reversals over longer horizons. Adopting the arguments of Baltas and Kosowski, this paper therefore suggests that the use of a larger sample both for time-series and crosssectional analysis provides one reason why strong reversals are not noted.

\subsection{Time-Series Momentum Strategies across Developed and Emerging Markets}

In order to further investigate time-series momentum across equity markets, equity indices are distinguished for developed and emerging markets. This allows examining whether time-series momentum patterns are similar in these two different types of market.

\section{[Insert Table IV here]}

Table IV provides evidence of the different behavior of time-series momentum with respect to developed and emerging markets. In particular, it can be noted that emerging markets experience much higher time-series momentum returns compared to developed 
markets. However, the time-series momentum phenomenon is of a shorter duration in the case of emerging markets. Indeed, the profitability of these strategies starts to dissipate much more quickly for emerging markets. To shed some light on this fundamental difference, we perform the same analysis, but this time we use local currency terms rather than the U.S. dollar.

An initial observation we make is that returns and Sharpe ratios appear enhanced in local terms (Part A of Table IV) compared to U.S. dollar terms (Part B of Table IV) in regard to both developed and emerging markets. For developed markets, returns are on average augmented by 34bps, but the biggest difference is noted for emerging markets whose returns are improved by 180bps. We also observe, that profits to time-series momentum in emerging markets are no longer short-term in nature once we control for the currency component. Instead, the lasting effect of time-series momentum appears very similar for both markets. These results make us consider that there might be differences in the return continuation patterns for developed and emerging currency returns. Hence, we isolate the currency return, based on the following equation:

$$
\operatorname{Rcurr}_{i, t}=\operatorname{RUSD} D_{i, t}-\text { Rlocal }_{i, t}
$$

where $R U S D_{i, t}$ is the return of index $i$ in month $t$ in U.S. dollar terms and Rlocal $_{i, t}$ is the return of index $i$ in month $t$ in local terms.

After extracting the currency component for each of the country indices, we examine its return continuation pattern by regressing the currency return for index $i$ in month $t$ on its own return lagged $h$ months, similar to the previous pooled panel regressions for the price continuation patterns. Thus, the pooled panel regression can be specified as follows:

$$
\operatorname{Rcurr}_{i, t}=\alpha+\beta_{h} \operatorname{Rcurr}_{i, t-h}+\varepsilon_{t}
$$

where $\operatorname{Rcurr}_{i, t}$ is the currency return of index $i$ in month $t$ and $\operatorname{Rcurr}_{i, t-h}$ is the currency return of index $i$ in month $t$ lagged $h$ months.

The regression defined in the above equation is a pooled panel regression in which all equity developed indices (23 in total) or emerging indices (22 in total) and dates are combined to generate the beta coefficients. The number of lags for each instrument extends to 60 months $(h=1,2, \ldots, 60)$, and thus 60 regressions are estimated.

\section{[Insert Figure 3 here]}


As expected, in Figure 3, we note that there is indeed return continuation in the currency component of the developed and emerging market equity indices. ${ }^{14}$ Similar to the price continuation patterns, there is a time-series continuation pattern for currencies which reverses or dissipates after the $12^{\text {th }}$ lag. It is interesting to see that the magnitude of this pattern is larger for emerging markets than for developed ones, especially with respect to the first lag, but also thereafter in some cases. We also see a slightly different pattern for emerging markets which exhibit significant and negative reversals for lags smaller than 12 (i.e., lags 7 and 11). These findings largely help to explain the different time-series momentum profitability for emerging and developed markets. We also show with these results that the higher short-term momentum profits can be attributed to higher time-series currency return predictability.

\subsection{Evaluating Time-Series Momentum Strategies}

Following the significant time-series momentum profitability observed above, this section aims to further investigate the abnormal performance of time-series momentum by estimating some standard asset pricing models. Specifically, the single diversified-acrossassets 12-1 time-series momentum strategy is investigated since, as already mentioned, it serves as a benchmark in the existing literature.

To better investigate the performance of time-series momentum strategies, we regress time-series momentum returns on a number of factors. This allows for better evaluation of the drivers of time-series momentum profitability. Attention is drawn to the single diversified ${ }^{15}$ 12-1 time-series momentum strategy, which serves as the benchmark in the momentum literature and refers to a strategy with a look-back period of 12 months and a holding period of 1 month. The specified model can be estimated as follows:

$$
\operatorname{TSMOM}_{t, i}^{(12,1)}=\alpha+\beta_{1} M S C I_{t}+\beta_{2} G S C I_{t}+\beta_{3} S M B_{t}+\beta_{4} H M L_{t}+\beta_{5} U M D_{t}+\varepsilon_{t}
$$

where $\operatorname{TSMOM}_{i, t}^{(12,1)}$ is the equally-weighted average return across instruments of the single diversified time-series momentum strategy in month $t$ for asset class $i$, with a look-back period of 12 months and a holding period of 1 month, $M S C I_{t}$ is the return of the MSCI World Index in month $t, G S C I_{t}$ is the return of the S\&P GSCI in month $t$, and the SMB, HML, and UMD regressors are Fama-French factors representing size, value, and momentum across U.S. stocks, respectively.

\footnotetext{
${ }^{14}$ This is consistent with the currency momentum findings documented by Menkhoff et al. (2012).

${ }^{15}$ In this study, diversified returns refers to equally-weighted average returns across all instruments.
} 
Given that the present dataset concerns instruments from different asset classes and markets, the strategy is further regressed on alternative factors, including momentum everywhere factors from Asness et al. (2013), and, as such, it better resembles the present dataset. These factors replace the Fama-French factors, which are limited to U.S. stocks. However, since the present dataset excludes foreign exchange markets as well as bond markets, the momentum everywhere factors are adjusted to reflect this change and to represent the dataset as closely as possible. Thus, the specified model can be written as:

$$
\operatorname{TSMOM}_{t, i}^{(12,1)}=\alpha+\beta_{1} \operatorname{MSCI}_{t}+\beta_{2} G S C I_{t}+\beta_{3} V A L_{t}+\beta_{4} M O M_{t}+\varepsilon_{t}^{16}
$$

where the first two regressors remain the same, while VAL and MOM represent value and momentum, respectively, and replace the Fama-French three-factor model.

\section{[Insert Table V here]}

Table V reports the risk-adjusted performance of the single diversified 12-1 timeseries momentum strategy. It can be observed that the strategy delivers large and significant alphas in all asset classes, indicating its out-performance relative to the benchmarks included in the regression.

The diversified time-series momentum strategy exhibits mainly significant beta coefficients on the cross-sectional momentum factor as proxied by UMD. The significance of momentum factor UMD is also confirmed with respect to the futures markets explored by Moskowitz et al. (2012) and Baltas and Kosowski (2013). This finding suggests that some variation in returns can be explained by cross-sectional momentum. None of the other factors included can explain the time-series momentum profitability, except for the commodity benchmark GSCI, which captures some of the time-series momentum profitability with regard to commodity indices. Nevertheless, the significance observed in the alpha coefficients implies that GSCI and UMD capture only a part of the time-series momentum profitability, leaving an important part unexplained.

As a next step, the 12-1 time-series momentum strategy is evaluated with respect to Equation (6), where the SMB, HML, and UMD factors of Fama and French are replaced with the momentum everywhere factors constructed by Asness et al. (2013).

\section{[Insert Table VI here]}

Table VI reports the risk-adjusted performance of the single diversified 12-1 time-

\footnotetext{
${ }^{16}$ The Variable Inflator Factor (VIF) test is available in the online appendix. Our results indicate that there are no concerns for multi-collinearity across the factors.
} 
series momentum strategy with the alternative control variables as specified previously. Once again, the strategy delivers significant alpha coefficients and loads significantly on the momentum factor (MOM). However, an important part of the time-series momentum profitability seems to remain unexplained. ${ }^{17}$

\section{Time-Series Momentum and International Mutual Fund Performance}

Following the presented evidence of significant time-series momentum profitability, this section aims to investigate the relation between mutual fund performance and time-series momentum. In particular, we examine the nature of investment strategies followed by a comprehensive list of international mutual funds, and consider whether these can be related to trend-following strategies such as time-series momentum.

Existing time-series momentum literature focuses primarily on hedge fund behavior, particularly that of managed futures funds and CTAs, which have been shown to follow timeseries momentum strategies (Baltas and Kosowski, 2013; Moskowitz et al., 2012). As far as mutual fund behavior is concerned, the existing literature focuses on mutual fund performance with respect to cross-sectional momentum (Grinblatt et al., 1995; Breloer et al., 2014). The findings suggest that mutual fund managers tend to be momentum investors who buy past winners but do not systematically sell past losers. In this study, we seek to investigate mutual fund performance with regard to time-series momentum strategies. More precisely, the monthly mutual fund returns net of management expenses and fees is regressed on 12-1 timeseries momentum returns. Given the more traditional and risk-averse nature of mutual funds, mutual fund returns are also regressed on the returns of a long-only time-series momentum strategy. The particular strategy used is one of long-only investments in instruments that have been performing well over the previous 12 months. In cases where there is a sell signal, the long-only time-series momentum involves investment in the three-month Treasury bill, which provides the risk-free rate. Hence, mutual fund performance according to these two strategies can be examined by the following models:

$$
\begin{aligned}
& M F_{y, t}=\alpha+\beta T S M O M_{i, t}^{(12,1)}+\varepsilon_{t} \\
& M F_{y, t}=\alpha+\beta \operatorname{Long}_{i, t}^{(12,1)}+\varepsilon_{t}
\end{aligned}
$$

\footnotetext{
${ }^{17}$ The significance of the momentum coefficients UMD and MOM implies that there exists an important relationship between cross-sectional and time-series momentum. In an unreported appendix, we investigate the relation between time-series and cross-sectional momentum. Results are available upon request.
} 
where $\operatorname{TSMOM}_{i, t}^{(12,1)}$ is the return of the single diversified time-series momentum strategy described previously, $\operatorname{Long}_{i, t}^{(12,1)}$ is the equally-weighted average return across instruments of the single long-only time-series momentum strategy in month $t$ for asset class $i$, with a lookback period of 12 months and a holding period of 1 month, and $M F_{y, t}$ is the equally average return across mutual funds of type $y$ in month $t$. Type $y$ refers to commodity, international, and global mutual funds. Both the standard time-series momentum strategy and the long-only strategy involve a look-back period of 12 months and a holding period of 1 month.

To better evaluate mutual fund performance, mutual fund returns are regressed on a specification model that includes certain control variables, as follows:

$$
\begin{gathered}
M F_{y, t}=\alpha+\beta_{1} \operatorname{TSMOM}_{i, t}^{(12,1)}+\beta_{2} M S C I_{t}+\beta_{3} G S C I_{t}+\beta_{4} V A L+\beta_{5} M O M+\varepsilon_{t} \\
M F_{y, t}=\alpha+\beta_{1} \operatorname{Long}_{i, t}^{(12,1)}+\beta_{2} M S C I_{t}+\beta_{3} G S C I_{t}+\beta_{4} V A L+\beta_{5} M O M+\varepsilon_{t}
\end{gathered}
$$

where the first regressors in both equations are the same as those in Equations (7) and (8), $M_{S C I}$ is the return of the MSCI World Index at time $t, G S C I_{t}$ is the return of the S\&P GSCI Index in month $t$, and $V A L$ and $M O M$ are the value and momentum everywhere factors from Asness et al. (2013).

\section{[Insert Table VII here]}

Table VII reports the alpha and beta coefficients of the models specified above. It can be observed in Panel A that international mutual funds exhibit small beta loadings for the 12-1 time-series momentum strategy with and without control variables and the $t$-statistics are not statistically different from zero. On the other hand, when we replace the 12-1 strategy with the long-only strategy, the beta exposures are much stronger both in the univariate and the multivariate model, and the $t$-statistics are always significant. ${ }^{18}$ When we look at the longonly strategy, the alpha coefficients become insignificant in the univariate model, implying that these types of fund returns can be largely explained by long-only trend following strategies. Besides, the $\mathrm{R}^{2}$ improves dramatically for each of the fund types examined. The above results suggest that international mutual funds have a tendency to focus on recent winners but do not sell past losers, which is in line with the cross-sectional momentum findings documented by Grinblatt et al. (1995).

\footnotetext{
${ }^{18}$ In unreported tests, we also replace the 12-1 strategy with the short-only strategy, and find that mutual funds have much smaller exposure on the short side. This is the case both with and without control variables. These results support the argument that international mutual funds do not systematically sell losers or exploit the shortside of time-series momentum due to various reasons and limitations.
} 
When we look at the model, including other control variables, the results show that time-series momentum, both in its long-short and long-only aspects, is unable to entirely capture mutual fund performance. With respect to equity funds, when we compare the MOM factor, which captures cross-sectional momentum, with the 12-1 time-series momentum strategy, it seems that the funds are more related to cross-sectional rather than time-series momentum strategies. This is not the case for the commodity funds, which exhibit higher sensitivity to time-series momentum. Given the more exotic nature of commodity funds compared to traditional equity funds, one might be interested to investigate the relation between these funds and CTAs. A final observation we make for the equity funds is that the market factor, along with value strategies, plays a much greater role in explaining performance, whereas with respect to commodity funds the market is the most determinant factor.

\section{[Insert Figure 4 here]}

We go one step further and examine how the relation between funds and some of the factors examined previously has evolved over time. It would be of a great interest to perform a time-series analysis of these relationships, since in this way we would be able to assess the effects of extreme values and establish common behaviors among the different fund groups. Figure 4, panels A, B, and C, provide this type of information with regard to developed, emerging, and commodity funds, respectively. For this purpose we estimate the following model:

$$
M F_{y, t}=\alpha+\beta_{1} \operatorname{TSMOM}_{i, t}^{(12,1)}+\beta_{2} \operatorname{MSCI}_{i, t}^{19}+\beta_{3} \operatorname{Winner}_{i, t}^{(12,1)}+\beta_{4} \operatorname{Loser}_{i, t}^{(12,1)}+\beta_{5} V A L+\varepsilon_{t}
$$

where the first two and the last regressors have been specified in the previous models, Winner $_{i, \boldsymbol{t}}^{(\mathbf{1 2 , 1 )}}$ is the equally-weighted average return across instruments of the 12-1 strategy decomposed into its winner portfolio in month $t$ for asset class $i$, and $\operatorname{Loser}_{\boldsymbol{i}, \boldsymbol{t}}^{(\mathbf{1 2}, \mathbf{1})}$ is the equally- weighted average return across instruments of the 12-1 strategy decomposed into its loser portfolio in month $t$ for asset class $i$.

As shown in the above equation, we further decompose the 12-1 TSMOM strategy into its winner (long positions) and loser (short positions) and regress fund returns on them. In cases where we notice an extreme market state, such that either the winner or the loser component does not exist for a particular month, we assign to it a return of zero. The graphs display the 36-month rolling $t$-statistics of the beta coefficients of the multivariate regression.

\footnotetext{
${ }^{19}$ GSCI in case of commodity funds
} 
The results of the $t$-statistics indicate distinct herding behavior of the different fund groups but also some common investment behavior for certain factors. What appears to be the most significant factor in explaining fund performance is clearly the market itself, measured as either the equity or commodity market. This is common among all the fund categories we examine, and the beta coefficients for the market factors are high and almost at all times significant. A second commonality among all fund types is the ability of the winner's portfolio in capturing fund performance, since the factor loading is positive and most of the times significant. The relation between fund returns and the loser's portfolio is negative and statistically different from zero the majority of times, and especially with respect to commodity and emerging market funds, confirming the findings of Grinblatt et al. (1995) with respect to losers.

Finally, we notice a fundamental difference in investment philosophy between commodity and equity funds. It seems that, on average, equity funds seek value as an investment strategy, whereas commodity funds can sometimes exhibit significantly negative coefficients on the commodity value factor (VAL). Interestingly, the positive relationship that the commodity funds exhibit with the winner portfolio over time is much more pronounced compared to that of equity funds.

\section{Market Conditions and the Role of Central Bank Intervention}

\subsection{Extreme Market Conditions}

In this section, the abnormal performance of the aggregate single diversified 12-1 time-series momentum strategy is evaluated with regard to the market portfolio as proxied by the MSCI World Index.

\section{[Insert Figure 5 here]}

Figure 5 shows the growth of an investment of \$100 in the aggregate 12-1 time-series momentum strategy and the MSCI World Index from 1971 to 2015. The figure clearly highlights the superior performance of time-series momentum relative to the market throughout the whole sample period. More remarkably, the figure presents the different responses of time-series momentum and the market during recession periods as defined by the NBER. ${ }^{20}$ During these recessions, time-series momentum generated large gains, whereas the market incurred large losses. Time-series momentum experienced similar large gains during uptrends of the market.

\footnotetext{
${ }^{20}$ National Bureau of Economic Research. Dates available at: http://www.nber.org/cycles/cyclesmain.html.
} 
An interesting case to note is the global financial crisis that took place from December 2007 through June 2009. During this contraction, time-series momentum experienced losses in the first stage of the downturn, then delivered substantial profits for a long period, and finally incurred severe losses when the market started recovering. This finding highlights the mechanism and the intuition behind time-series momentum. During normal market trends, time-series momentum sets up long and short positions in instruments according to the signs of their cumulative return over a look-back period. For instance, if the market has been increasing (decreasing) over the look-back period, then time-series momentum will set up long (short) positions for most instruments. When the market experiences a reversal in either direction, time-series momentum will initially incur large losses due to its existing long or short positions. Subsequently, time-series momentum will benefit from this reversal and experience large profits since it will adjust its positions to the new market conditions. Time-series momentum strategies are therefore highly profitable precisely when reversals continue for long horizons. The fact that time-series momentum experiences large gains during market downtrends highlights its use as a hedge for market losses and makes the explanation for the time-series momentum profitability less plausible from a risk-compensation perspective. The following figure displays the relation between time-series momentum and the market during recessions further.

\section{[Insert Figure 6 here]}

Figure 6 presents the realized cumulative returns of the market and the 12-1 timeseries momentum strategy during the stress periods throughout the sample period. The figure highlights the high profitability and out-performance of time-series momentum during these recessions and the losses experienced by the market. It is clear that time-series momentum substantially outperformed the MSCI index in four out of six stress periods, delivering positive returns. Remarkably, the most striking differences can be observed during the global financial crisis, when the aggregate strategy delivered a surprising $17 \%$, whereas the market portfolio experienced almost a $44 \%$ loss.

These results confirm those explored in the time-series momentum literature on futures markets and further support the hedging nature of trend-following strategies in different asset classes. This is intuitive, given that financial crises occur gradually and so time-series momentum strategies have enough time to adjust to long and short positions according to their cumulative returns over a certain look-back period. The hedging nature of the strategy under investigation is further explored in Figure 7. 


\section{[Insert Figure 7 about here]}

Figure 7 plots the monthly returns of the 12-1 time-series momentum against those of the MSCI World Index. The figure highlights the option-like behavior of time-series momentum. The "smile" indicates that the strategy performs best in extreme up-or-down market conditions. Fung and Hsieh (2001) demonstrate that trend-following strategies generate payoffs that are similar to an option straddle on the market, which is also the case in this figure. Indeed, the payoff shown in Figure 7 resembles that of an option straddle. This implies that returns on time-series momentum may not be due to compensation for market crashes, which renders the explanation for time-series momentum profitability even more puzzling from a risk-adjusted perspective (Moskowitz et al., 2012). ${ }^{21}$

\subsection{The Future of Time-Series Momentum and the Role of Central Banks}

In considering the performance of time-series momentum after the end of the global financial crisis in Figure 2, some would doubt its future and abnormal profitability (e.g., Baltas and Kosowski, 2013, 2015). Although the cumulative return on the 12-1 time-series momentum strategy remains well above the market index, it seems that it entered a consolidation period for the first time during, and throughout, the sample period. In contrast, the market seems to have entered a new uptrend over the same period and the time-series momentum unexpectedly does not deliver substantial profits.

\section{[Insert Table VIII here]}

Interestingly, this observation coincides with periods of market intervention by central banks, which have adopted quantitative easing as a monetary policy, to stimulate the global economy. We suspect that this aggressive policy has also caused correlations across assets to be distorted, thereby threatening the trend-following patterns. To underpin this argument, we first examine the correlations across all equity and commodity indices with respect to three crucial periods, as illustrated in Table VIII: pre-QE, at-QE, and post-QE. The first observation we make is that the examined assets are much more highly correlated in the pre-

\footnotetext{
${ }^{21}$ In unreported tests, we also examine the properties of short term momentum strategies. E.g. we construct a 31 time-series momentum strategy similar to the 12-1 but with a look-back period of 3 months. We look at the cumulative performance of the single diversified 3-1 time-series momentum strategy and we make the same observations as with the 12-1.The strategy outperforms the broad market to a great extent over the examined period and also outperforms the 12-1 strategy. It also realizes its largest profits during established and continuous trends of the market, as well as during bad market states. We explore further the superiority of the shorter-term strategy when the market rebounds and when the market crashes during stress periods. We find that the 3-1 strategy outperforms the 12-1 strategy in 8 out of 10 market rebounds and in 6 out of 10 market crashes. Because of that, we also observe that the 3-1 time-series momentum "smile" is more pronounced compared to the 12-1 strategy, rendering the former a better hedge in extreme market states.
} 
QE period than in the at-QE period, with correlations spiking in $98 \%$ of the observations. ${ }^{22}$ We then examine the same relation between the at-QE period and the post-QE period, and remarkably we notice that correlations have been normalizing back towards their previous pre-crisis levels, which holds true for $66 \%$ of the observations. To further strengthen our argument we perform regression tests to investigate whether there is indeed any relationship between our strategy and money printing adopted by the Federal Reserve Bank. We examine this relationship as follows.

$$
\operatorname{TSMOM}_{t, i}^{(12,1)}=\alpha+\beta_{1} \operatorname{MSCI}_{t}+\beta_{2} G S C I_{t}+\beta_{3} M O M_{t}+\beta_{4} V A L_{t}+\beta_{5} Q E_{t}+\varepsilon_{t}
$$

where $\operatorname{TSMOM}_{i, t}^{(12,1)}, \mathrm{MSCI}_{t}, \mathrm{GSCI}_{t}, \mathrm{MOM}_{t}$, and $V A L_{t}$ are the regressors used in the previous sections, while the new variable $Q E_{t}$ is a dummy variable that takes the value of 1 in times where the Federal Reserve Bank is engaged in any QE program and the value of 0 otherwise.

We examine this sensitivity with respect to the various index categories to see the variability of the results. The results are reported in Table IX, where we can clearly see significant negative impacts of QE on the time-series momentum profitability. The impact is not particularly strong for the commodity indices that we examine, implying that their inclusion in the momentum strategy is highly diversifying. In fact, in unreported results we experiment with two different time-series momentum strategies, one including the commodity indices and one including only the equity ones, and we note that the former outperformed the latter during the QE period, whereas in earlier periods, the sample with the equity indices did slightly better.

\section{[Insert Table IX here]}

These findings may suggest that, over the last few years, there have not been any distinct trend patterns across assets that time-series momentum could exploit so as to realize large gains. According to these results, it is reasonable to argue that time-series momentum has been threatened over recent years and that restoring correlations across assets to their normal pre-crisis levels may play a crucial role in recovering time-series momentum attractiveness. It would also be interesting for future studies to examine the behavior of timeseries momentum as we move further away from the end of the QE era.

\footnotetext{
${ }^{22}$ This refers to all the indices we examined. Here we just report a sample, covering only the G7 countries along with the aggregate commodity benchmark.
} 


\section{Conclusion}

We document a significant time-series momentum effect that has been consistent and robust across global equity and commodity markets over the past half century. Our results confirm those documented for futures markets, and a degree of market inefficiency in equity and commodity indices can be suspected.

By examining return predictability across all instruments, this study depicts continuation patterns in monthly returns for the first 12 months and weaker reversals over longer horizons. These results are consistent with behavioral theories of initial under-reaction and delayed over-reaction by investors (Barberis, Shleifer and Vishny, 1998; Daniel, Hirshleifer and Subrahmanyam, 1998; Hong and Stein, 1999) and with the potential profitability of trend-following strategies.

Based on the existence of return predictability, we further construct time-series momentum strategies over various combinations of look-back and holding periods, and evaluate their profitability. We find that time-series momentum strategies exhibit strong and consistent performance across all asset classes for the first 12 months and subsequently decay or exhibit weaker reversals. These findings are consistent and robust across a number of subsamples, combinations of look-back and holding periods, and different sample periods.

Additionally, we investigate how time-series momentum behaves with respect to developed and emerging markets, and we find that, when we do not consider the currency impact, emerging markets tend to exhibit shorter-term but stronger time-series momentum. When we do control for the currency impact, the time-series momentum results for the two markets look much more similar, implying a strong currency trend-following pattern that is stronger for emerging markets.

Time-series momentum has little exposure to standard asset pricing factors, but seems to be highly related to all of the momentum factors examined and to the market in some cases. When examining developed and emerging markets separately, it seems that time-series momentum could be largely captured by the momentum and the market factors. This is not the case for commodity indices, however, where the strategy remains unexplained. Additionally, evidence has been found regarding the hedging nature of time-series momentum. In particular, time-series momentum delivers payoffs that are similar to those of an option straddle; it realizes its largest gains during extreme up-or-down market conditions.

Over the last few years, correlations across assets have increased due to central bank interventions. Consequently, there are fewer independent trend patterns from which timeseries momentum can benefit. Indeed, we find that time-series momentum has negative and 
significant exposure in quantitative easing periods, which strengthen this intuition.

All types of international mutual funds that we examine follow time-series momentum strategies to some extent, but overall they have a preference for long-only trendfollowing strategies, value investing, and index tracking. In fact, when we examine the loadings on the loser component of time-series momentum, they exhibit negative and significant coefficients for almost the entire period.

The evidence of time-series momentum in conventional asset classes directly challenges the random walk hypothesis and renders the theoretical background of market efficiency more puzzling. Besides, its high return premium in extreme market movements seems to contradict rational asset pricing explanations. The present findings are therefore more likely to support behavioral explanations, such as theories of sentiment, which further challenge the notion of efficient financial markets. The veracity of rational theories that explain time-series momentum should not be excluded, however, and may be fruitful subjects for future research.

The findings of this study have some important implications and offer new insights into the investment world. Specifically, they prove that trend-following strategies can be equally associated with asset classes and fund industries other than only futures markets, managed futures funds, and CTAs. Given the increasing availability of international ETFs, which are benchmarked to global equity and commodity indexes, our study provides evidence that investment opportunities that can be exploited are numerous and involve different asset classes. It would be worthwhile and challenging, however, to examine whether time-series momentum could be an appropriate investment strategy for private investors, considering the transaction costs and the frequency of transactions that this strategy demands and whether trend-following remains an attractive investment philosophy in light of intervention by central banks and the high levels of correlation across assets.

\section{References}

Asness, C., Moskowitz, T. J. and Pedersen, L. H. (2013) Value and momentum everywhere The Journal of Finance 68(3), 929-985.

Ball, R. and Kothari, S. P. (1989) Nonstationary expected returns: Implications for tests of market efficiency and serial correlation in returns, Journal of Financial Economics 25(1), 5174.

Baltas, A.N. and Kosowski, R. (2013), Momentum strategies in futures markets and trendfollowing funds, Imperial College Business School Working Paper.

Baltas, A.N. and Kosowski, R. (2015) Demystifying time-series momentum strategies: volatility estimators, trading rules and pairwise correlations, SSRN eLibrary. 
Barberis, N., Shleifer, A. and Vishny, R. (1998) A model of investor sentiment, Journal of Financial Economics 49(3), 307-343.

Barroso, P. and Santa-Clara, P. (2015) Momentum has its moments, Journal of Financial Economics 116(1), 111-120.

Breloer, B., Scholz, H. and Wilkens, M. (2014) Performance of international and global equity mutual funds: Do country momentum and sector momentum matter?, Journal of Banking and Finance 43, 58-77.

Carhart, M.M. (1997) On persistence in mutual fund performance, Journal of Finance 52(1), 57-82.

Chordia, T. and Lakshmanan, S. (2006) Earnings and price momentum, Journal of Financial Economics 80(3), 627-656.

Chordia, T. and Shivakumar, L. (2002) Momentum, business cycle, and time-varying expected returns, Journal of Finance 57(2), 985-1019.

Choong, C., Lai, S. and Wu, Y. (2008) Effective fair pricing of international mutual funds, Journal of Banking and Finance 32, 2307-2324.

Conrad, J. and Kaul, G. (1998) An anatomy of trading strategies, Review of Financial Studies 11(3), 489-519.

Cumby, R.E. and Glen, J.D. (1990) Evaluating the performance of international mutual funds, Journal of Finance 45, 497-521.

Daniel, K., Hirshleifer, D. and Subrahmanyam, A. (1998) A theory of overconfidence, selfattribution, and instrument market under- and over-reactions, Journal of Finance 53, 18391885.

Daniel, K. and Moskowitz, T. J. (2016) Momentum crashes Journal of Financial Economics, Forthcoming.

De Bondt, W.F.M. and Thaler, R. (1985) Does the stock market overreact?, Journal of Finance 40(3), 793-805.

Fama, E. (1970) Efficient capital markets: A review of theory and empirical work, Journal of Finance 25(2), 383-417.

Fama, E. and French, K. 1993) Common risk factors in the returns on stocks and bonds, Journal of Financial Economics 3(3), 3-56.

Fama, E. and French, K. (1996) Multifactor explanations of asset pricing anomalies, Journal of Finance 51(1), 55-84.

Fung, W. and Hsieh, D. (2001) The risk in hedge fund strategies: Theory and evidence from trend followers, Review of Financial Studies 14(2), 313-341.

Goetzmann, W., Ivkovic, Z. and Rouwenhorst, G. (2001) Day trading international mutual funds Journal of Financial and Quantitative Analysis 36, 287-309.

Goldman Sachs, 2014. Goldman Sachs S\&P GSCI Commodity Index. Available at: http://www.goldmansachs.com/what-we-do/instruments/products-andbusinessgroups/products/gsci/approach.html

Grinblatt, M., Titman S. and Wermers, R. (1995) Momentum investment strategies, portfolio performance, and herding: A study of mutual fund behavior, American Economic Review 85 (5), 1088-1105. 
Grundy, B. and Martin, S. (2001) Understanding the nature of risks and the sources of rewards to momentum investing, Review of Financial Studies 14(1), $29-78$.

Griffin, J.M., Ji, X. and Martin, S. (2003) Momentum investing and business cycle risk: Evidence from pole to pole, Journal of Finance 58(6), 2515-2547.

Hong, H. and Stein, J.C. (1999) A unified theory of under-reaction, momentum trading, and over-reaction in asset markets, Journal of Finance 54(6), 2143-2184.

Hurst, B., Ooi, Y.H. and Pedersen, L.H. (2014), A century of evidence on trend-following investing, AQR Capital Working Paper.

Hurst, B., Ooi, Y.H. and Pedersen, L.H. (2012) Demystifying managed futures, Journal of Investment Management, forthcoming.

Jegadeesh, N. (1990) Predictable behavior of instrument returns, Journal of Finance 45(3), 881-898.

Jegadeesh, N. and Titman, S. (1993) Returns to buying winners and selling losers: Implications for stock market efficiency, Journal of Finance 48(1), 65-91.

Jegadeesh, N. and Titman, S. (2001) Profitability of momentum strategies: An evaluation of alternative explanations, Journal of Finance 56(2), 699-720.

Lehmann, B.N. (1990) Fads, martingales, and market efficiency, Quarterly Journal of Economics 105(1), 1-28.

Lintner, J. (1965) The valuation of risk assets and the selection of risky investments in stock portfolios and capital budgets, Review of Economics and Statistics 47(1), 13-37.

Lo, A. and MacKinlay, C. (1990) When are contrarian profits due to stock market reaction?, Review of Financial Studies, 3(2), 175-205.

Menkhoff, L., Sarno, L., Schmeling, M. and Schrimpf, A. (2012) Currency momentum strategies, Journal of Financial Economics 106, 620-684.

Moskowitz, T.J. and Grinblatt, M. (1999) Does industry explain momentum?, Journal of Finance 1249-1290.

Moskowitz, T.J., Ooi, Y.H. and Pedersen, L.H. (2012) Time-series momentum, Journal of Financial Economics 104(2), 228-250.

MSCI.com, 2014. Index definitions. Available at:

www.msci.com/products/indexes/tools/index.html\#WORLD

Rouwenhorst, K.G. (1998) International momentum strategies, Journal of Finance 53(1), 267-284.

Sharpe, W.F. (1964) Capital asset prices: A theory of market equilibrium under conditions of risk, Journal of Finance 19(3), 425-442.

Yao, Y. (2012) Momentum, contrarian and the January seasonality, Journal of Banking and Finance 36(10), 2757-2769. 


\section{Figure 1: Time-Series Return Predictability}

This figure reports the $t$-statistics of the beta coefficients for the pooled panel linear regression of monthly excess returns for all instruments combined on their own past monthly excess returns for lags $h=1,2, \ldots, 60$. The $t$-statistics are calculated using standard errors that are clustered by asset and time. The monthly returns are also scaled by their realized volatility over the same period. The dashed lines represent significance level at 5\%. The sample covers the period January 1970 through August 2015.
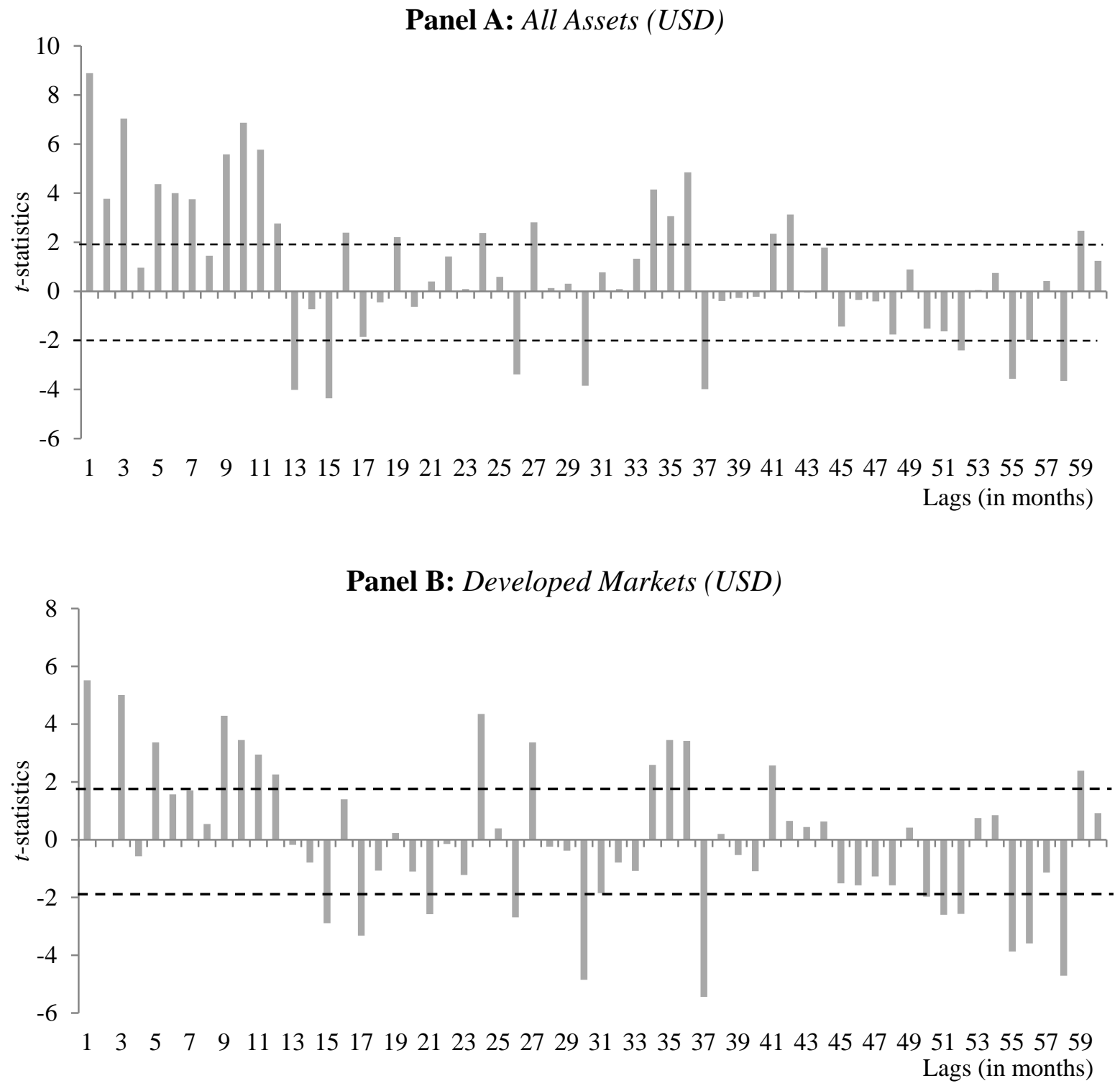

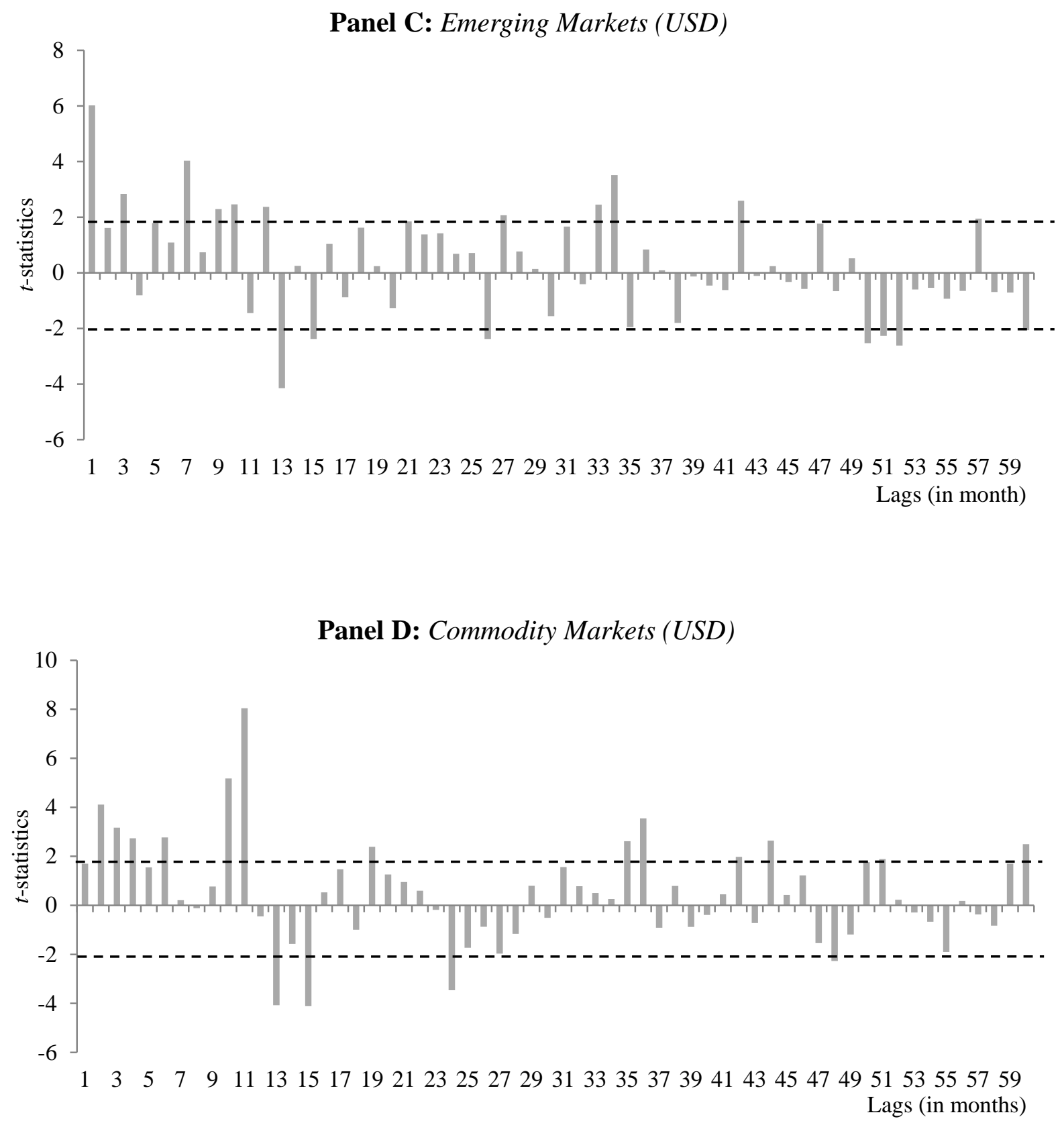
Figure 2: International Equity and Commodity Funds Geographical Distribution

We collect the universe of international mutual funds from Morningstar Direct from 1969 to 2015. Our dataset includes 1,177 international equity funds and 106 commodity funds. Panel A chart reports the investment areas in which the funds are concentrated. The classification is based on the Morningstar Category, Investment Area and Primary Prospectus Benchmark. Panel B chart reports the commodity sector in which the funds are concentrated. The classification is based on the Morningstar Category and Global Investment Funds Sectors (GIFS).

Panel A: International Equity Funds

\section{International Equity Funds - Investment Area Concetration}

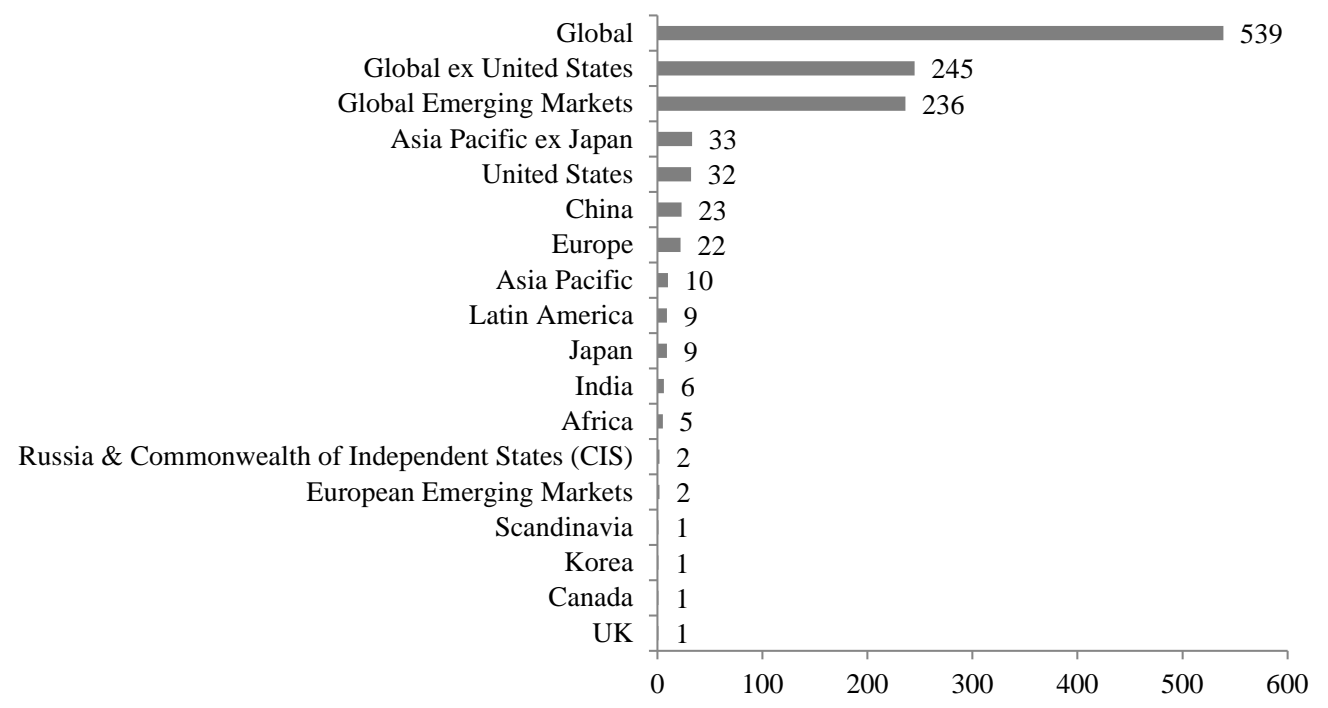

Panel B: Commodity Funds Commodity Distribution

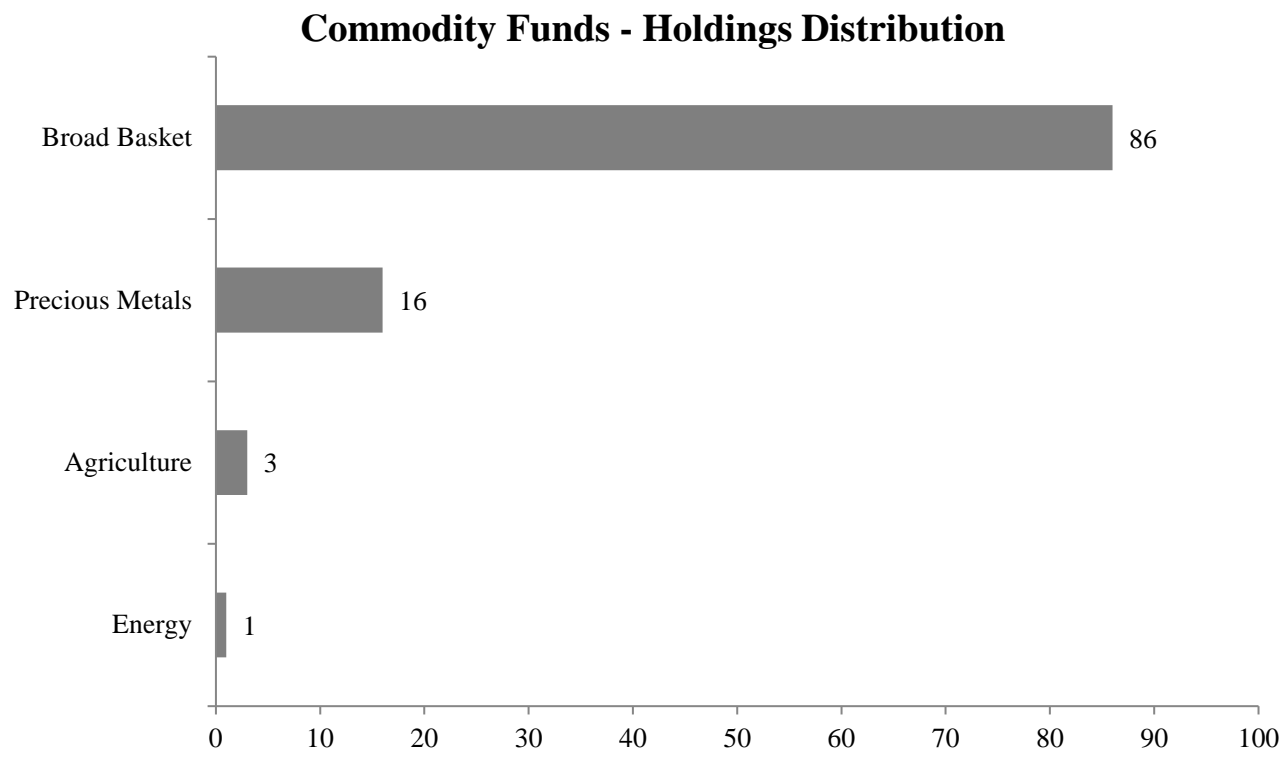


Figure 3: Time-Series Currency Return Predictability

This figure reports the $t$-statistics of the beta coefficients for the pooled panel linear regression of monthly returns of the currency components across all developed and emerging markets, combined separately, on their own past monthly returns for lags $h=1,2, \ldots, 36$. The $t$-statistics are calculated using standard errors that are clustered by asset and time. The dashed lines represent significance level at 5\%. The sample covers the period from January 1970 through August 2015.

Panel A: Developed Market Currency

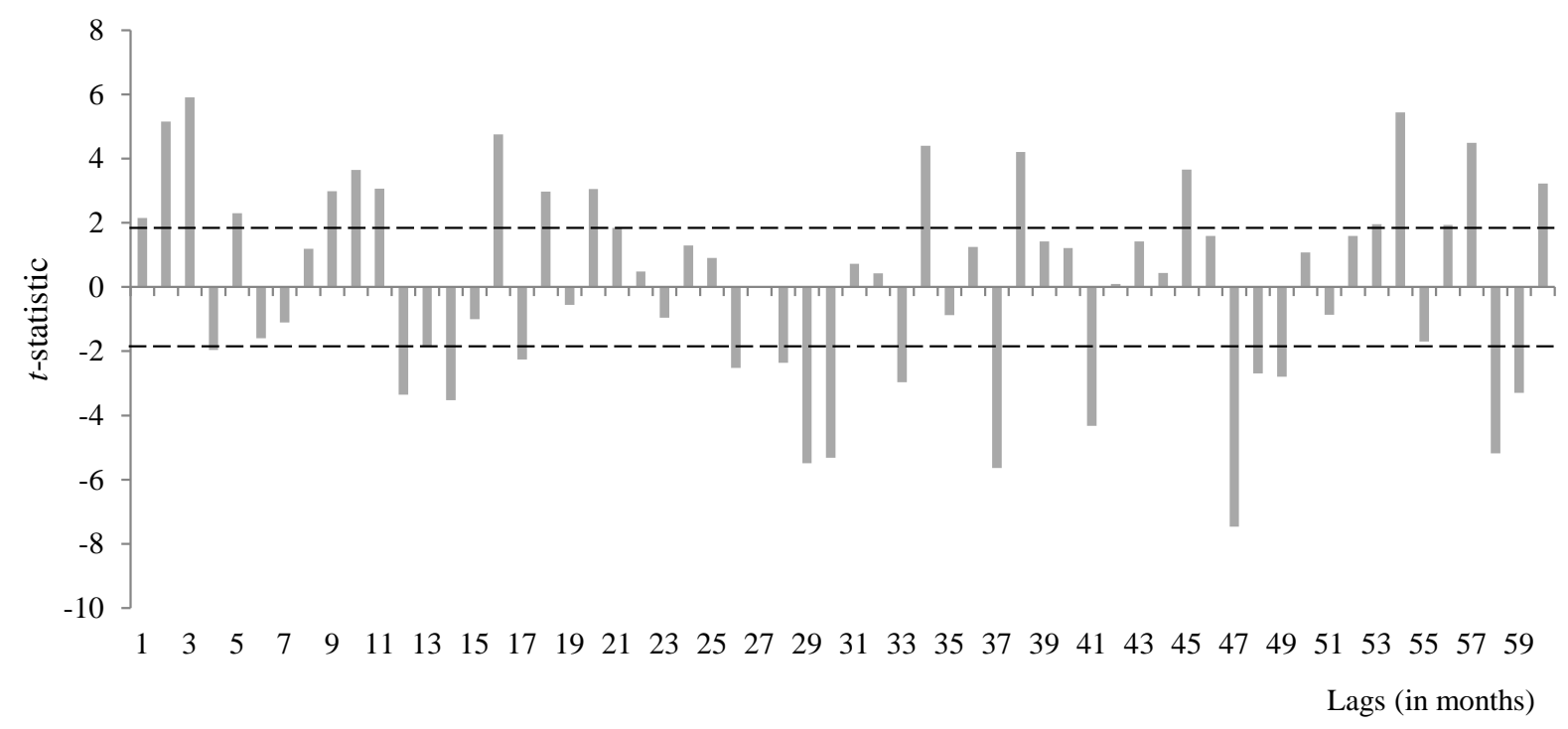

Panel B: Emerging Market Currency

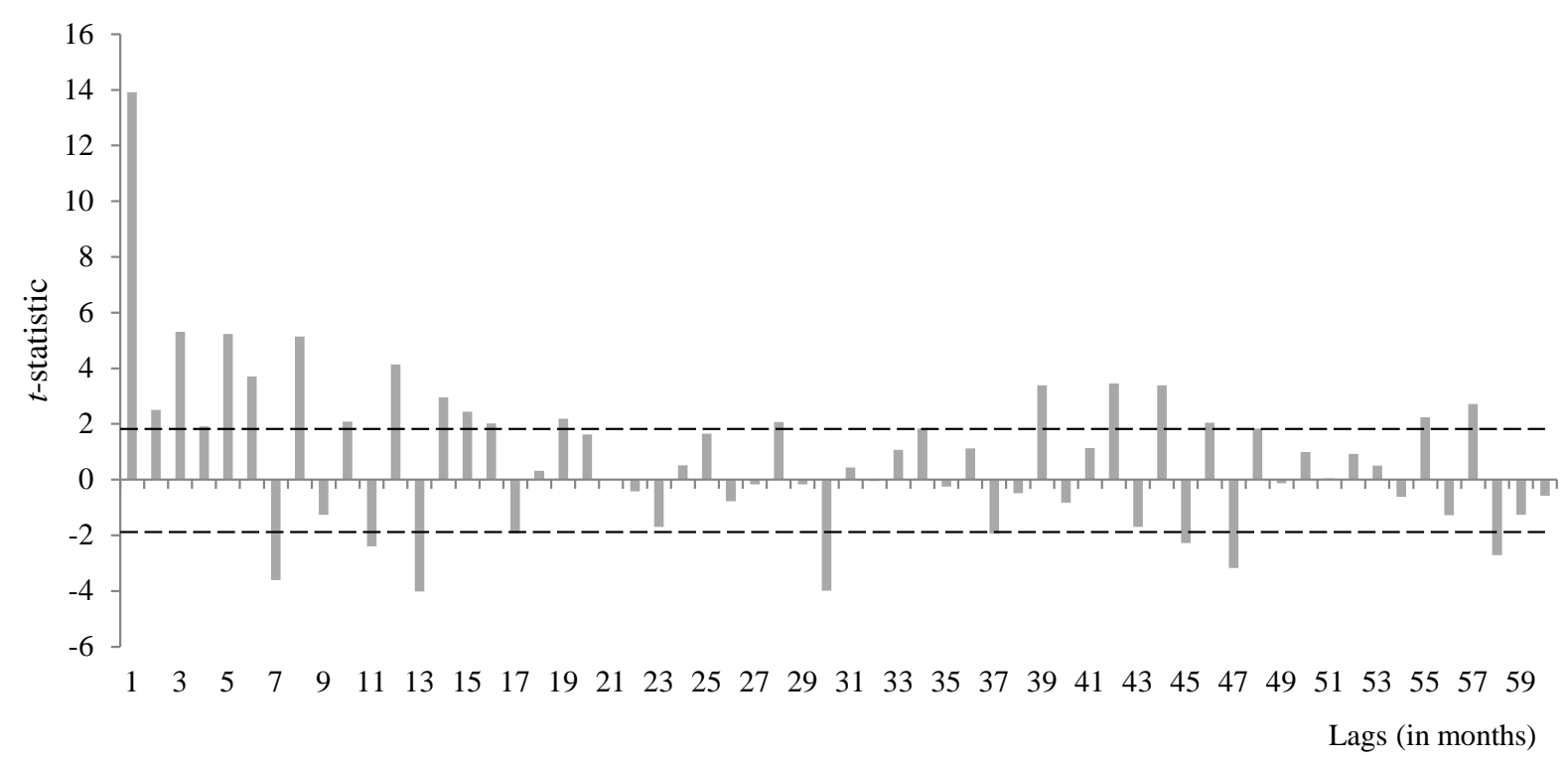


Figure 4: Mutual Fund Performance and Factors over Time

Panel A graph reports the Newey-West $t$-statistics of the beta coefficients from the 36-month rolling multivariate regression of International Developed Market Mutual Fund returns on the MSCI World Index, the S\&P GSCI Commodity Index, the single diversified 12-1 time-series momentum strategy (TSMOM), the winner and loser portfolios of the 12-1 time-series momentum strategy, the 12-1 longonly time-series momentum strategy, and the VAL and MOM factors. The sample covers the period starting from February 1971 through August 2015. Panel B reports the Newey-West $t$-statistics of the beta coefficients from the 36-month rolling multivariate regression of International Emerging Mutual Fund returns on the MSCI World Index, the S\&P GSCI Commodity Index, the single diversified 12-1 time-series momentum strategy (TSMOM), the winner and loser portfolios of the 12-1 time-series momentum strategy, the 12-1 long-only time-series momentum strategy, and the VAL and MOM factors. The sample covers the period from October 1989 through August 2015. Panel C reports the $t$ statistics of the beta coefficients from the 36-month rolling multivariate regression of International Commodity Mutual Fund returns on the MSCI World Index, the S\&P GSCI Commodity Index, the single diversified 12-1 time-series momentum strategy (TSMOM), the winner and loser portfolios of the 12-1 time-series momentum strategy, the 12-1 long-only time-series momentum strategy, and the VAL and MOM factors. The sample covers the period starting from November 1997 through August 2015.

Panel A: Developed Markets

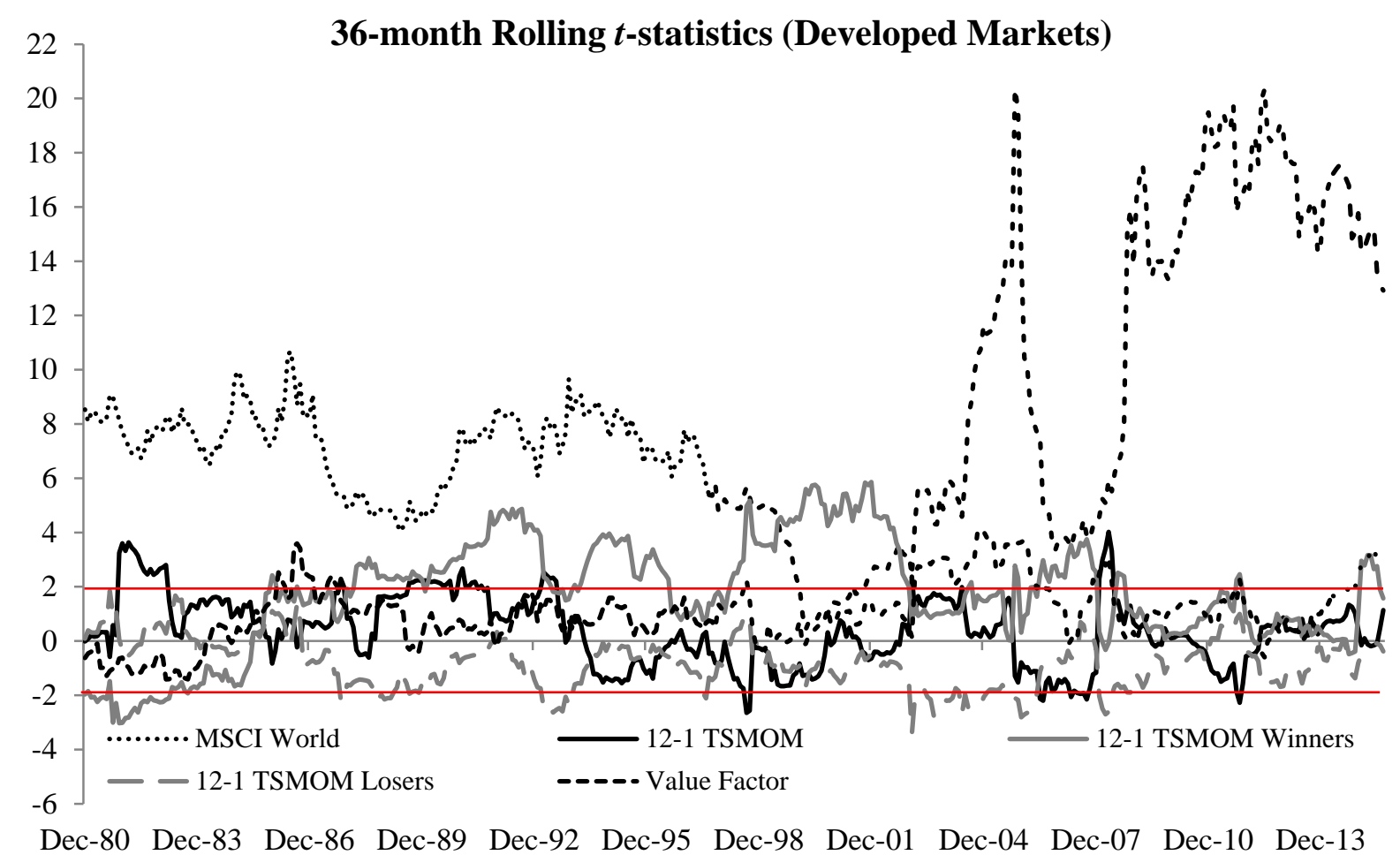


Panel B: Emerging Markets

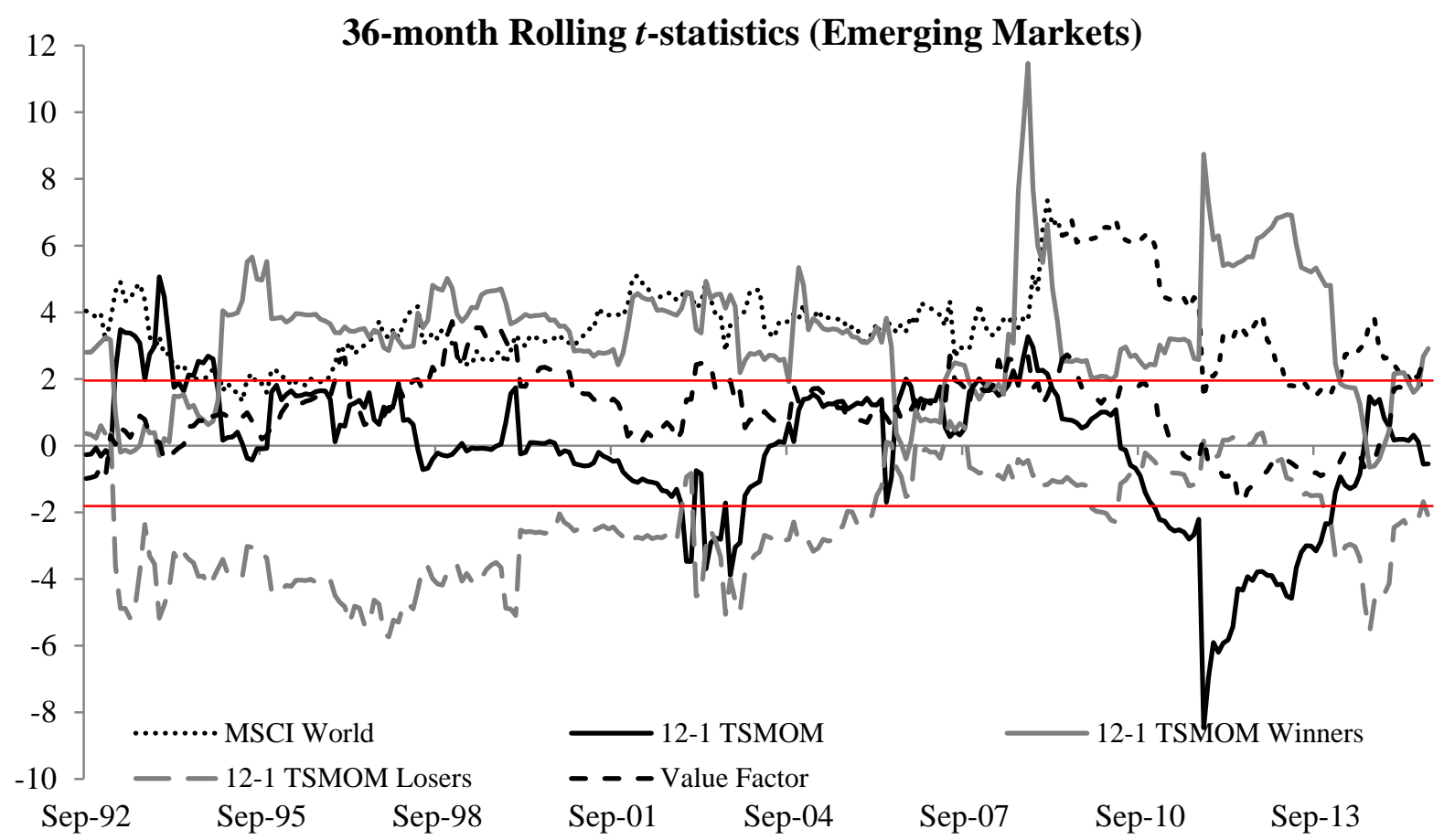

Panel C: Commodity Funds

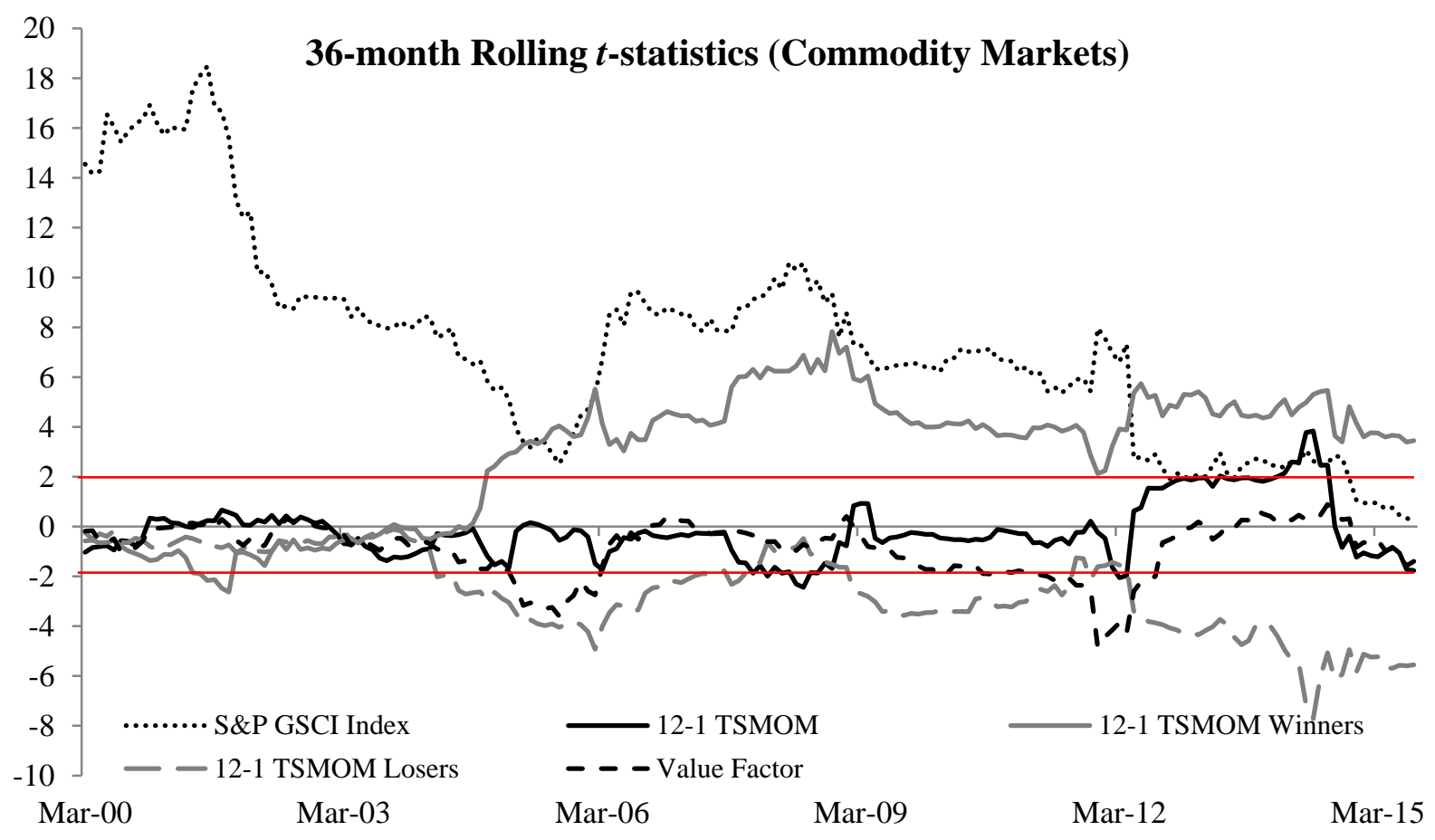


Figure 5: Historical Performance of the Time-Series Momentum Strategy

The figure presents the growth of a $\$ 100$ investment in the single diversified 12-1 time-series momentum strategy and the MSCI World Index. The sample covers the period from January 1971 through August 2015. The figure also highlights the recession periods defined by the NBER; the oil crisis November 1973-March 1975, the “double dip” recession January 1980-July 1980, the early 1980s recession July 1981-November 1982, the oil price shock July 1990-March 1991, the dot-com bubble March 2001-November 2001 and the Great Recession December 2007-June 2009.

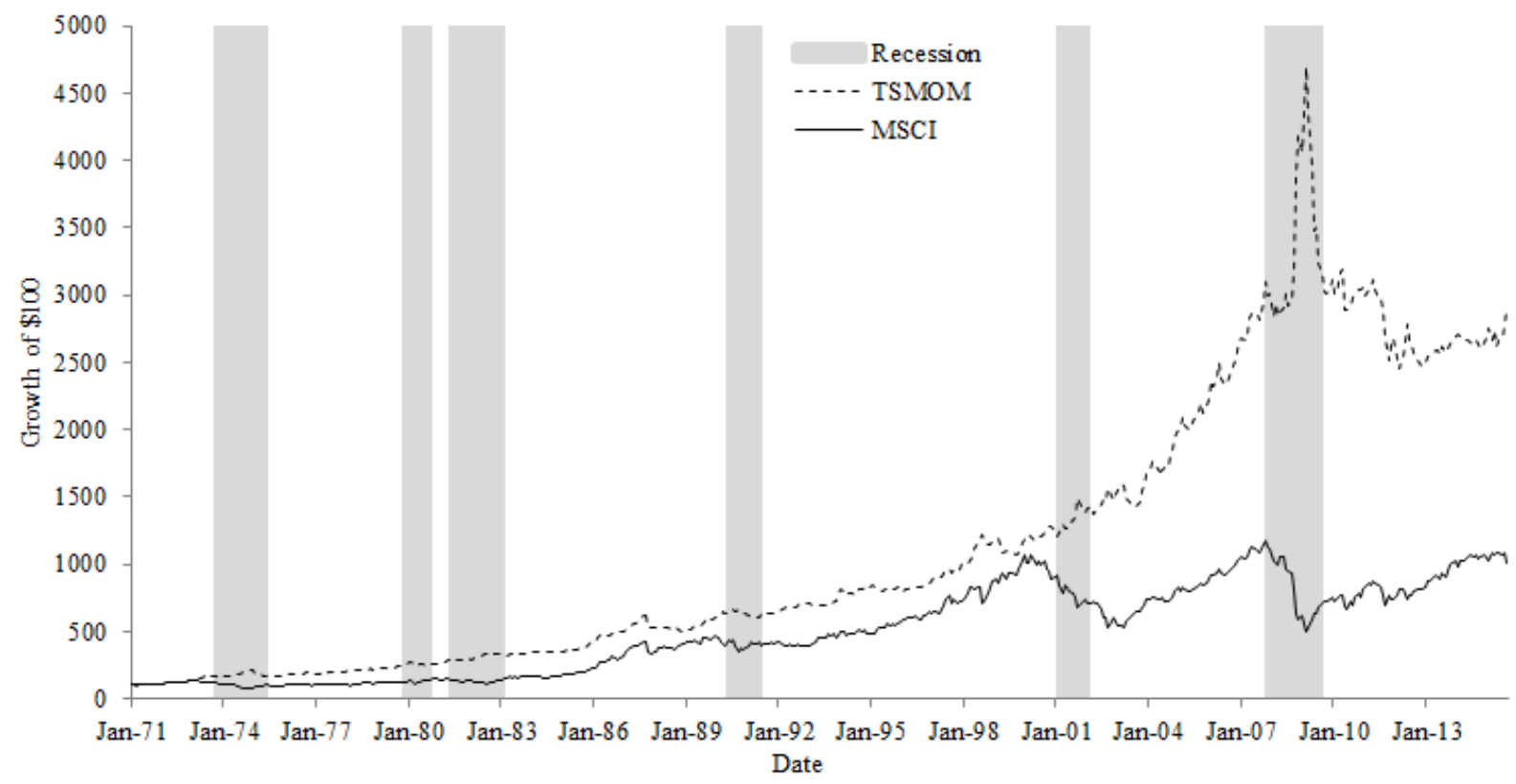

Figure 6: Option-like Behavior of Time-Series Momentum

The figure presents the cumulative returns of the single diversified 12-1 time-series momentum strategy and the MSCI World Index during recession periods defined by NBER.

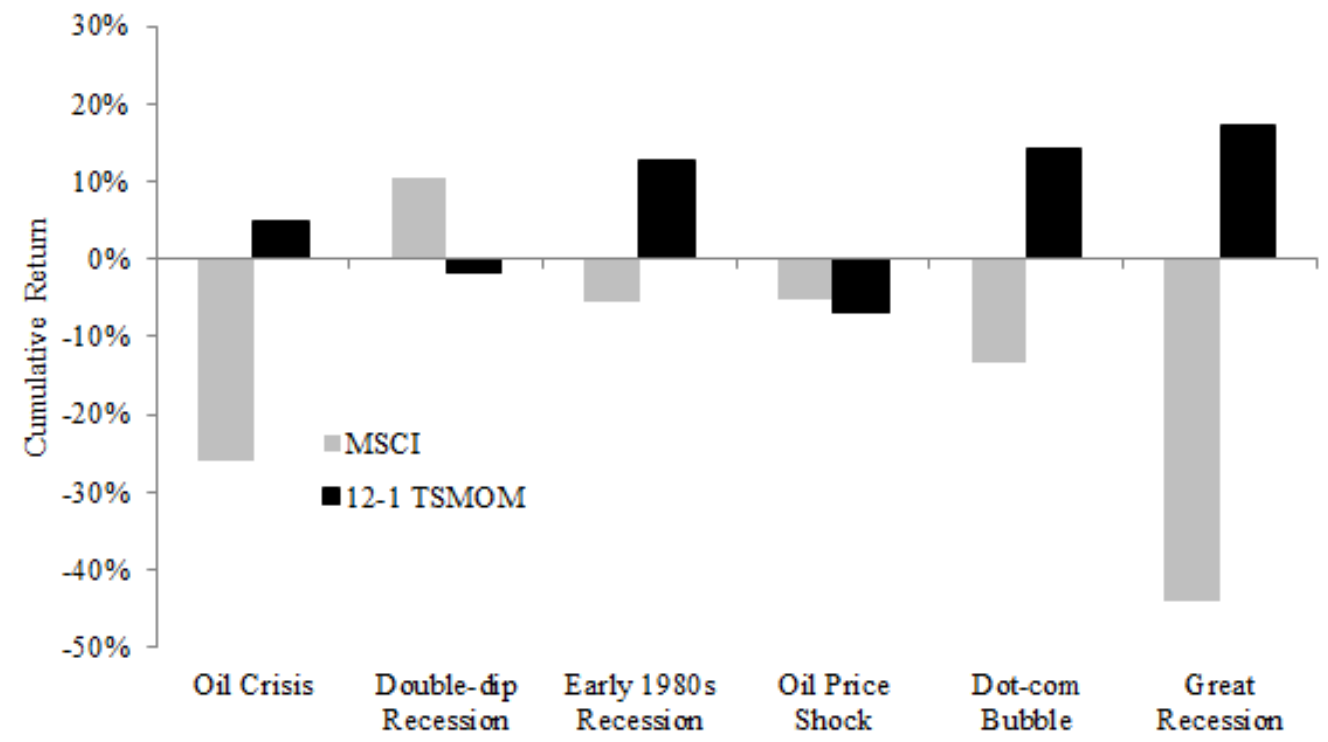


Figure 7: Time-Series Momentum "Smile”

The figure presents the scatterplot of monthly returns of the single diversified 12-1 time-series momentum against the returns of the MSCI World Index. The dashed lines represent the quadratic fit. The sample covers the period January 1971 through August 2015.

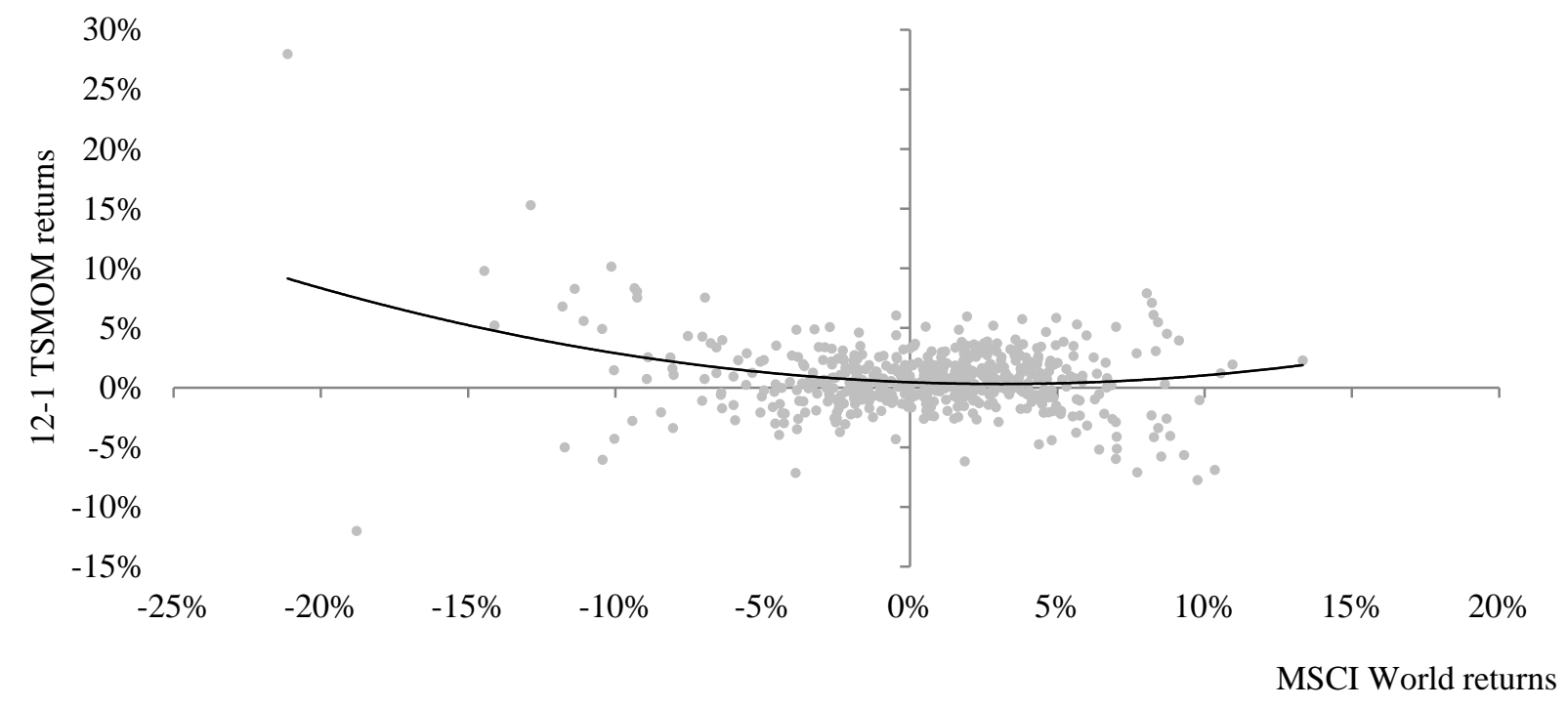


Table I: Descriptive Statistics: Equity and Commodity Indices

The table reports summary statistics for equity and commodity indices. The annualized mean, annualized volatility (standard deviation), skewness, and kurtosis are reported. The sample covers the period from December 1969 through August 2015.

\begin{tabular}{|c|c|c|c|c|}
\hline & $\begin{array}{l}\text { Annualized Mean } \\
\text { Return (\%) }\end{array}$ & $\begin{array}{c}\text { Annualized } \\
\text { Volatility (\%) }\end{array}$ & Skewness & Kurtosis \\
\hline \multicolumn{5}{|c|}{ Equity Indices - Developed Markets } \\
\hline Australia & 3.08 & 19.63 & -1.71 & 15.71 \\
\hline Austria & 1.72 & 23.98 & -0.92 & 6.51 \\
\hline Belgium & 3.81 & 20.80 & -1.22 & 8.29 \\
\hline Canada & 3.85 & 19.95 & -0.87 & 3.48 \\
\hline Denmark & 8.21 & 19.61 & -0.46 & 2.33 \\
\hline Finland & 4.42 & 25.38 & -0.36 & 3.38 \\
\hline France & 3.43 & 22.68 & -0.46 & 1.48 \\
\hline Germany & 3.95 & 22.15 & -0.65 & 1.84 \\
\hline Hong Kong & 3.66 & 34.08 & -0.53 & 7.30 \\
\hline Ireland & -0.17 & 17.81 & -1.11 & 6.28 \\
\hline Israel & 0.71 & 16.60 & -0.55 & 4.90 \\
\hline Italy & -1.06 & 25.62 & -0.15 & 0.67 \\
\hline Japan & 5.22 & 20.88 & -0.01 & 0.74 \\
\hline Netherlands & 5.20 & 19.42 & -0.81 & 2.79 \\
\hline New Zealand & 0.08 & 21.95 & -0.99 & 7.89 \\
\hline Norway & 2.57 & 27.76 & -0.80 & 2.89 \\
\hline Portugal & -2.85 & 18.40 & -0.52 & 4.57 \\
\hline Singapore & 2.19 & 26.62 & -0.61 & 7.37 \\
\hline Spain & 0.37 & 23.80 & -0.52 & 2.18 \\
\hline Sweden & 6.55 & 23.99 & -0.48 & 1.43 \\
\hline Switzerland & 7.17 & 18.13 & -0.39 & 1.36 \\
\hline UK & 3.17 & 21.33 & 0.30 & 5.57 \\
\hline USA & 5.36 & 15.38 & -0.67 & 2.53 \\
\hline \multicolumn{5}{|c|}{ Equity Indices - Emerging Markets } \\
\hline Brazil & 9.08 & 51.24 & -1.34 & 10.86 \\
\hline Chile & 6.62 & 24.29 & -0.55 & 2.57 \\
\hline China & -8.00 & 34.15 & 0.00 & 1.63 \\
\hline Colombia & 1.14 & 21.98 & -0.37 & 4.88 \\
\hline Czech Republic & 0.62 & 19.30 & -0.72 & 7.74 \\
\hline Egypt & 1.91 & 21.41 & 0.22 & 7.73 \\
\hline Greece & -6.84 & 29.72 & -0.27 & 6.91 \\
\hline Hungary & -0.72 & 25.83 & -1.36 & 12.90 \\
\hline India & 1.10 & 21.09 & -0.19 & 4.44 \\
\hline Indonesia & -2.33 & 34.91 & 0.32 & 11.06 \\
\hline Malaysia & 0.25 & 21.40 & -0.27 & 9.77 \\
\hline Mexico & 5.87 & 24.03 & -1.01 & 7.42 \\
\hline Philippines & 0.92 & 23.41 & -0.15 & 5.53 \\
\hline Poland & -0.43 & 30.14 & 0.88 & 15.54 \\
\hline Qatar & -0.73 & 14.05 & -1.37 & 20.15 \\
\hline South Africa & 2.16 & 14.67 & -1.06 & 12.02 \\
\hline Taiwan & -1.46 & 26.73 & -0.02 & 4.95 \\
\hline Thailand & -1.74 & 28.70 & -0.64 & 6.28 \\
\hline Turkey & -5.99 & 41.56 & 0.01 & 4.02 \\
\hline United Arab Emirates & -0.99 & 20.90 & -0.62 & 22.01 \\
\hline Peru & 2.19 & 22.35 & -0.83 & 9.56 \\
\hline Korea & -1.13 & 27.39 & 0.32 & 7.31 \\
\hline
\end{tabular}


Table I (Continued)

\begin{tabular}{lcccc}
\hline Commodity Indices & & & & \\
\hline Crude Oil & -1.67 & 32.92 & -0.15 & 1.61 \\
Gold & -1.72 & 15.57 & -0.03 & 1.41 \\
Brent Crude Oil & 3.13 & 32.00 & -0.64 & 2.09 \\
Copper & 0.16 & 27.38 & -0.37 & 4.23 \\
Natural Gas & -35.87 & 51.41 & -0.06 & 0.63 \\
Live Stock & 0.03 & 13.74 & -0.49 & 0.62 \\
Corn & -8.13 & 27.00 & 0.22 & 2.13 \\
Silver & -6.54 & 28.16 & -0.13 & 1.37 \\
Zinc & -3.38 & 25.40 & -0.50 & 3.55 \\
Sugar & -11.27 & 31.75 & 0.03 & 0.78 \\
Soybeans & -0.47 & 23.88 & -0.29 & 1.11 \\
Cocoa & -7.20 & 28.35 & 0.18 & 0.76 \\
Heating Oil & -1.51 & 31.40 & -0.01 & 1.19 \\
Aluminum & -3.93 & 19.14 & -0.06 & 0.54 \\
Nickel & -4.09 & 34.33 & -0.14 & 0.43 \\
Coffee & -8.86 & 36.33 & 0.52 & 1.84 \\
Lean Hogs & -5.64 & 24.12 & -0.37 & 0.84 \\
Palladium & 0.21 & 35.35 & -0.25 & 2.30 \\
Petroleum & -0.66 & 30.87 & -0.17 & 1.73 \\
Wheat & -8.26 & 27.04 & 0.02 & 1.43 \\
Cotton & -4.62 & 25.87 & -0.05 & 0.73 \\
Live Cattle & 1.49 & 13.12 & -0.82 & 4.40 \\
\hline
\end{tabular}




\section{Table II: International Equity and Commodity Funds Descriptive Statistics}

The table reports sample descriptive statistics for the funds that existed at any time between December 1968 and August 2015, with the total sample including 1177 international equity funds and 106 commodity funds. Monthly Net Cash Flow for fund $j$ in month $t$ is computed as $\mathrm{NCF}_{\mathrm{j}, \mathrm{t}}=\mathrm{NCF}_{\mathrm{j}, \mathrm{t}^{-}}$ $\left[\mathrm{NCF}_{\mathrm{j}, \mathrm{t}-1}\left(1+\mathrm{r}_{\mathrm{j}, \mathrm{t}}\right)\right]$. Statistics for commodity funds concern shorter data starting from April 1997, alongside that for Total Net Assets and Net Cash Flow; for equity funds data starts from January 1990. Statistics are based on the monthly cross-sectional mean for each measure.

\begin{tabular}{|c|c|c|c|c|c|c|c|}
\hline \multicolumn{8}{|c|}{ Panel A: International Equity Funds (Developed Markets) } \\
\hline & Mean & Median & $\begin{array}{c}25^{\text {th }} \\
\text { Percentile } \\
\end{array}$ & $\begin{array}{c}75^{\text {th }} \\
\text { Percentile } \\
\end{array}$ & Max & Min & $\begin{array}{c}\text { Standard } \\
\text { Deviation }\end{array}$ \\
\hline Total Net Assets (\$ millions) & 823.05 & 691.74 & 351.90 & 1248.20 & 2565.87 & 19.48 & 565.71 \\
\hline Monthly Net Cash Flow (\$ millions) & -3.19 & 0.53 & -29.92 & 26.77 & 148.26 & -160.97 & 50.80 \\
\hline Expense Ratio (\%/year) & 1.40 & 1.37 & 1.30 & 1.44 & 2.37 & 1.14 & 0.23 \\
\hline Turover (\%/year) & 63.68 & 63.05 & 58.10 & 73.04 & 88.28 & 12.90 & 14.88 \\
\hline Fund Age (years) & 13.08 & 10.67 & 5.85 & 19.73 & 46.75 & 0.00 & 9.10 \\
\hline Monthly Allocation to Equity (\%) & 93.92 & 94.89 & 92.23 & 96.11 & 107.60 & 76.65 & 3.66 \\
\hline Monthly Allocation to non-US Equity (\%) & 65.40 & 68.59 & 60.59 & 73.37 & 97.60 & 0.00 & 15.31 \\
\hline Monthly Net Return (\%) & 0.84 & 1.01 & -1.69 & 3.93 & 13.63 & -22.48 & 4.54 \\
\hline Monthly Gross Return (\%) & 0.96 & 1.12 & -1.58 & 4.05 & 13.76 & -22.39 & 4.54 \\
\hline \multicolumn{8}{|c|}{ Panel B: International Equity Funds (Emerging Markets) } \\
\hline & Mean & Median & $\begin{array}{c}25^{\text {th }} \\
\text { Percentile } \\
\end{array}$ & $\begin{array}{c}75^{\text {th }} \\
\text { Percentile } \\
\end{array}$ & Max & Min & $\begin{array}{l}\text { Standard } \\
\text { Deviation } \\
\end{array}$ \\
\hline Total Net Assets (\$ millions) & 1153.94 & 1140.85 & 939.13 & 1275.56 & 2225.71 & 1.50 & 311.28 \\
\hline Monthly Net Cash Flow (\$ millions) & -7.90 & 1.64 & -46.93 & 47.33 & 293.52 & -332.28 & 93.97 \\
\hline Expense Ratio (\%/year) & 1.57 & 1.55 & 1.43 & 1.71 & 2.37 & 0.98 & 0.29 \\
\hline Turover (\%/year) & 53.32 & 57.17 & 44.34 & 67.35 & 88.66 & 9.43 & 22.42 \\
\hline Fund Age (years) & 8.82 & 4.92 & 1.92 & 15.04 & 46.75 & 0.00 & 8.93 \\
\hline Monthly Allocation to Equity (\%) & 90.54 & 92.21 & 87.96 & 94.63 & 99.94 & 71.62 & 5.12 \\
\hline Monthly Allocation to non-US Equity (\%) & 76.12 & 79.24 & 73.75 & 82.67 & 144.61 & 0.00 & 11.31 \\
\hline Monthly Net Return (\%) & 1.11 & 1.39 & -1.65 & 4.17 & 16.92 & -26.86 & 5.26 \\
\hline Monthly Gross Return (\%) & 1.25 & 1.51 & -1.52 & 4.29 & 17.07 & -26.75 & 5.27 \\
\hline \multicolumn{8}{|l|}{ Panel C: Commodity Funds } \\
\hline & Mean & Median & $\begin{array}{c}25^{\text {th }} \\
\text { Percentile }\end{array}$ & $\begin{array}{c}75^{\text {th }} \\
\text { Percentile }\end{array}$ & Max & Min & $\begin{array}{l}\text { Standard } \\
\text { Deviation }\end{array}$ \\
\hline Total Net Assets (\$ millions) & 575.20 & 561.96 & 130.27 & 854.42 & 1954.84 & 1.40 & 450.25 \\
\hline Monthly Net Cash Flow (\$ millions) & 18.59 & 7.92 & -5.10 & 35.35 & 384.22 & -172.19 & 64.41 \\
\hline Expense Ratio (\%/year) & 1.48 & 1.51 & 1.34 & 1.65 & 1.82 & 1.07 & 0.21 \\
\hline Turover (\%/year) & 101.13 & 10.95 & 1.22 & 68.08 & 1140.85 & -7.90 & 283.11 \\
\hline Fund Age (years) & 6.20 & 5.25 & 3.75 & 8.50 & 18.50 & 1.25 & 3.50 \\
\hline Monthly Allocation to Cash (\%) & 47.44 & 46.01 & 38.85 & 53.23 & 90.37 & 4.87 & 13.94 \\
\hline Monthly Allocation to Equity (\%) & 12.41 & 11.53 & 6.88 & 18.35 & 70.43 & -0.04 & 10.56 \\
\hline Monthly Net Return (\%) & 0.26 & 0.37 & -3.33 & 3.82 & 15.25 & -24.46 & 5.55 \\
\hline Monthly Gross Return (\%) & 0.37 & 0.45 & -3.26 & 4.03 & 15.37 & -24.33 & 5.58 \\
\hline
\end{tabular}


Table III: Time-Series Momentum Strategies across All Asset Classes

The table reports the annualized mean returns and the annualized Sharpe ratios for time-series momentum strategies across all asset classes in USD with a look-back period of $J$ months and a holding period of $K$ months. The sample covers the period January 1970 through August 2015. Significance at the $1 \%$ and $5 \%$ are denoted as $* * *$ and $* *$, respectively.

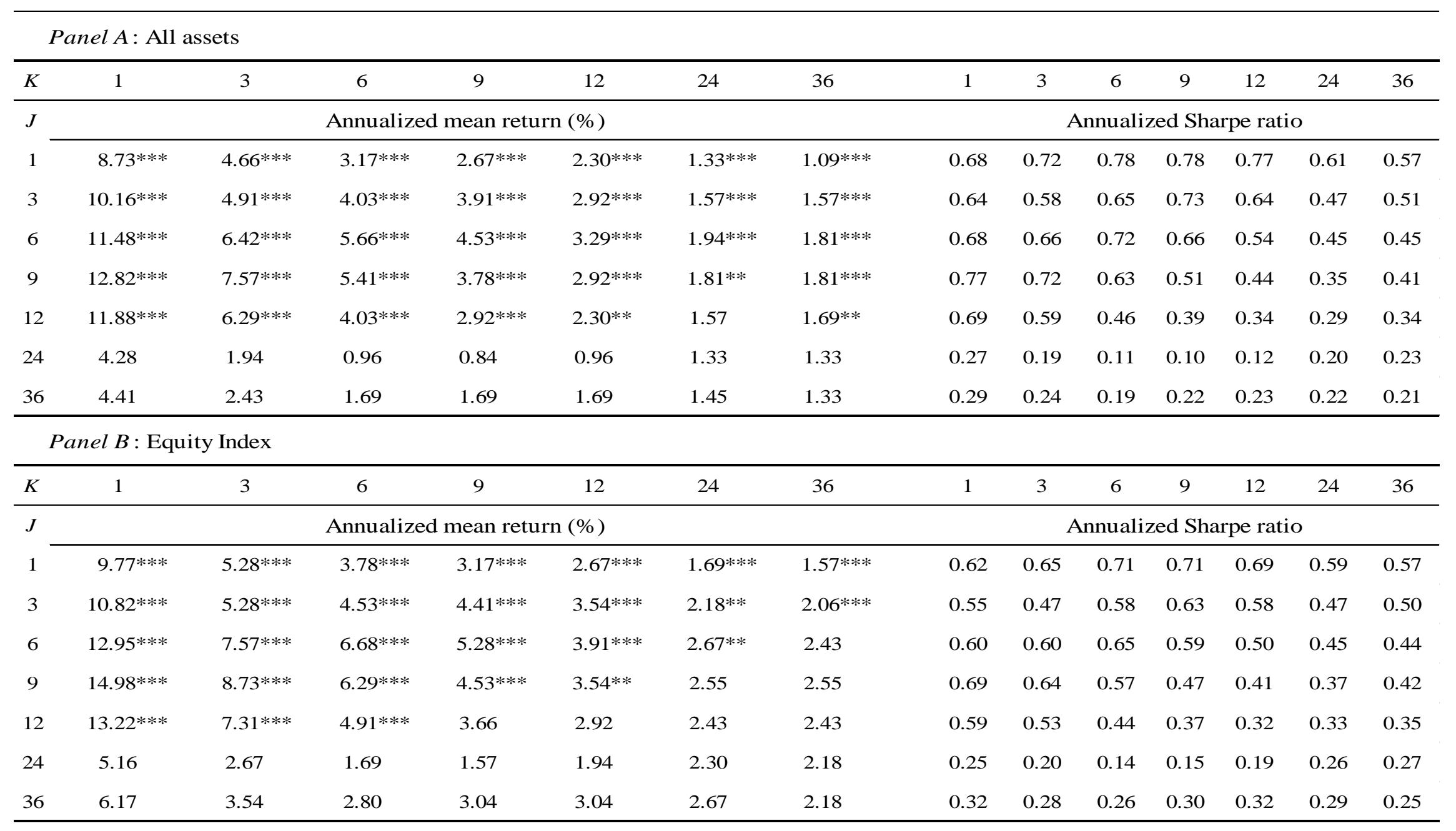




\begin{tabular}{|c|c|c|c|c|c|c|c|c|c|c|c|c|c|c|}
\hline$K$ & 1 & 3 & 6 & 9 & 12 & 24 & 36 & 1 & 3 & 6 & 9 & 12 & 24 & 36 \\
\hline$J$ & \multicolumn{7}{|c|}{ Annualized mean return (\%) } & \multicolumn{7}{|c|}{ Annualized Sharpe ratio } \\
\hline 1 & $6.42 * * *$ & $3.41 * * *$ & $2.18 * * *$ & $1.69 * * *$ & $1.45^{* * *}$ & 0.48 & 0.24 & 0.48 & 0.53 & 0.47 & 0.47 & 0.47 & 0.23 & 0.16 \\
\hline 3 & $8.86^{* * *}$ & $4.53 * * *$ & $2.80 * * *$ & $3.04 * * *$ & $1.81^{* * *}$ & 0.48 & 0.48 & 0.55 & 0.51 & 0.43 & 0.56 & 0.40 & 0.14 & 0.17 \\
\hline 6 & $8.60 * * *$ & $4.16^{* * *}$ & $3.66 * * *$ & $2.92 * * *$ & $1.94 * *$ & 0.60 & 0.60 & 0.53 & 0.43 & 0.49 & 0.46 & 0.33 & 0.15 & 0.20 \\
\hline 9 & $8.99 * * *$ & $5.41 * * *$ & $3.54 * * *$ & $2.30 * *$ & 1.69 & 0.36 & 0.48 & 0.54 & 0.53 & 0.43 & 0.33 & 0.27 & 0.06 & 0.12 \\
\hline 12 & $9.25 * * *$ & $4.41 * * *$ & 2.18 & 1.69 & 1.21 & 0.00 & 0.24 & 0.57 & 0.44 & 0.26 & 0.23 & 0.18 & 0.00 & 0.06 \\
\hline 24 & 2.80 & 0.72 & -0.36 & -0.60 & -0.96 & -0.72 & -0.48 & 0.16 & 0.06 & -0.06 & -0.09 & -0.13 & -0.13 & -0.10 \\
\hline 36 & 1.33 & 0.12 & -0.84 & -1.07 & -1.19 & -0.96 & -0.36 & 0.08 & 0.00 & -0.09 & -0.13 & -0.16 & -0.15 & -0.07 \\
\hline
\end{tabular}


Table IV: Time-Series Momentum Strategies across Equity Markets in USD and Local Terms

Part A reports the annualized mean returns and the annualized Sharpe ratios for time-series momentum strategies across equity markets in USD with a lookback period of $J$ months and a holding period of $K$ months. Park B reports the annualized mean returns and the annualized Sharpe ratios for time-series momentum strategies across equity markets in local terms with a look-back period of $J$ months and a holding period of $K$ months. The sample covers the period January 1970 through August 2015. Significance levels of $1 \%$ and $5 \%$ are denoted as *** and **, respectively.

\section{Part A: Time-Series Momentum Strategies across Equity Markets in USD terms}

\begin{tabular}{|c|c|c|c|c|c|c|c|c|c|c|c|c|c|c|}
\hline K & 1 & 3 & 6 & 9 & 12 & 24 & 36 & 1 & 3 & 6 & 9 & 12 & 24 & 36 \\
\hline$J$ & \multicolumn{7}{|c|}{ Annualized mean return (\%) } & \multicolumn{7}{|c|}{ Annualized Sharpe ratio } \\
\hline 1 & $5.54 * * *$ & $4.66^{* * *}$ & $3.17^{* * *}$ & $2.67 * * *$ & $2.67 * *:$ & $1.45^{* *}$ & $1.09 * * *$ & 0.14 & 0.16 & 0.17 & 0.17 & 0.18 & 0.12 & 0.11 \\
\hline 3 & $7.06^{* * *}$ & $4.66^{* * *}$ & $3.91^{* * *}$ & $4.03^{* * *}$ & $3.54^{* *:}$ & $1.69 * *$ & $1.45^{* *}$ & 0.14 & 0.13 & 0.15 & 0.16 & 0.14 & 0.10 & 0.09 \\
\hline 6 & $6.80^{* * *}$ & $6.04 * * *$ & $5.91^{* * *}$ & $5.54^{* * *}$ & $4.41^{* *:}$ & $2.30 * *$ & 1.57 & 0.16 & 0.15 & 0.17 & 0.16 & 0.14 & 0.10 & 0.08 \\
\hline 9 & $6.93^{* * *}$ & $6.93^{* * *}$ & $6.17^{* * *}$ & $5.16^{* * *}$ & $4.03^{* *:}$ & 2.06 & 1.69 & 0.17 & 0.17 & 0.16 & 0.13 & 0.11 & 0.07 & 0.07 \\
\hline 12 & $6.80^{* * *}$ & $6.42^{* * *}$ & $5.41^{* * *}$ & $4.28^{* * *}$ & $3.04 * *$ & 1.57 & 1.33 & 0.16 & 0.15 & 0.13 & 0.11 & 0.08 & 0.06 & 0.06 \\
\hline 24 & $4.41^{* * *}$ & $3.91^{* *}$ & 2.80 & 2.18 & 1.94 & 1.69 & 1.45 & 0.10 & 0.09 & 0.07 & 0.06 & 0.05 & 0.05 & 0.04 \\
\hline 36 & 2.80 & 2.30 & 1.69 & 1.69 & 1.69 & 1.21 & 0.72 & 0.06 & 0.05 & 0.04 & 0.04 & 0.04 & 0.03 & 0.02 \\
\hline \multicolumn{15}{|c|}{ Panel B: Emerging Markets (USD) } \\
\hline K & 1 & 3 & 6 & 9 & 12 & 24 & 36 & 1 & 3 & 6 & 9 & 12 & 24 & 36 \\
\hline$J$ & \multicolumn{7}{|c|}{ Annualized mean return (\%) } & \multicolumn{7}{|c|}{ Annualized Sharpe ratio } \\
\hline 1 & $10.03^{* * *}$ & $7.44^{* * *}$ & $4.03^{* * *}$ & $3.54^{* * *}$ & $2.92 * *$ & 1.33 & $1.45^{* * *}$ & 0.22 & 0.19 & 0.18 & 0.17 & 0.13 & 0.11 & 0.13 \\
\hline 3 & $11.22^{* * *}$ & $5.79 * * *$ & $4.16^{* *}$ & $4.41^{* * *}$ & $3.17^{* *}$ & 1.33 & 1.69 & 0.15 & 0.10 & 0.13 & 0.13 & 0.10 & 0.06 & 0.10 \\
\hline 6 & $8.60 * * *$ & $6.80^{* * *}$ & $6.17^{* * *}$ & $4.66^{* *}$ & 2.55 & 1.33 & 1.69 & 0.14 & 0.13 & 0.14 & 0.10 & 0.05 & 0.06 & 0.08 \\
\hline 9 & $9.38^{* * *}$ & $8.60^{* * *}$ & $5.79 * *$ & 3.17 & 1.57 & 1.21 & 1.94 & 0.17 & 0.14 & 0.11 & 0.05 & 0.03 & 0.05 & 0.07 \\
\hline 12 & $7.96 * * *$ & $6.17^{* *}$ & 2.92 & 0.96 & 0.00 & 0.84 & 1.45 & 0.12 & 0.09 & 0.04 & 0.00 & -0.01 & 0.03 & 0.05 \\
\hline 24 & -1.43 & -2.37 & -2.96 & -2.73 & -1.79 & 0.24 & 0.48 & -0.04 & -0.05 & -0.06 & -0.05 & -0.03 & 0.01 & 0.02 \\
\hline 36 & 1.81 & 1.57 & 0.84 & 1.45 & 1.57 & 1.09 & 0.48 & 0.03 & 0.02 & 0.02 & 0.03 & 0.04 & 0.03 & 0.01 \\
\hline
\end{tabular}


Part B: Time-Series Momentum Strategies across Equity Markets in Local Terms

Panel A: Developed Markets (Local)

\begin{tabular}{|c|c|c|c|c|c|c|c|c|c|c|c|c|c|c|}
\hline$K$ & 1 & 3 & 6 & 9 & 12 & 24 & 36 & 1 & 3 & 6 & 9 & 12 & 24 & 36 \\
\hline$J$ & \multicolumn{7}{|c|}{ Annualized mean return (\%) } & \multicolumn{7}{|c|}{ Annualized Sharpe ratio } \\
\hline 1 & $6.17^{* * *}$ & $4.53^{* * *}$ & $3.41^{* * *}$ & $3.04^{* * *}$ & $3.17^{* * *}$ & $1.57^{* * *}$ & $1.21^{* * *}$ & 0.18 & 0.20 & 0.19 & 0.21 & 0.21 & 0.13 & 0.11 \\
\hline 3 & $6.68^{* * *}$ & $5.16^{* * *}$ & $4.16^{* * *}$ & $4.53^{* * *}$ & $4.03^{* * *}$ & $2.18^{* * *}$ & $1.69 * * *$ & 0.16 & 0.16 & 0.16 & 0.19 & 0.17 & 0.12 & 0.11 \\
\hline 6 & $7.44^{* * *}$ & $5.79 * * *$ & $6.04 * * *$ & $5.79 * * *$ & $4.66^{* * *}$ & $2.43 * * *$ & $1.69 * *$ & 0.17 & 0.17 & 0.19 & 0.18 & 0.16 & 0.11 & 0.08 \\
\hline 9 & $7.44^{* * *}$ & $7.19 * * *$ & $6.93 * * *$ & $5.79 * * *$ & $4.53^{* * *}$ & $2.30 * *$ & 1.81 & 0.20 & 0.20 & 0.19 & 0.16 & 0.13 & 0.08 & 0.08 \\
\hline 12 & $8.21^{* * *}$ & $7.06^{* * *}$ & $5.79 * * *$ & $4.78^{* * *}$ & $3.66^{* * *}$ & 1.94 & 1.45 & 0.19 & 0.17 & 0.15 & 0.13 & 0.11 & 0.07 & 0.06 \\
\hline 24 & $4.53^{* * * *}$ & $4.03 * * *$ & $3.29 * *$ & 2.80 & 2.30 & 1.57 & 1.45 & 0.11 & 0.10 & 0.09 & 0.07 & 0.06 & 0.05 & 0.05 \\
\hline 36 & $3.29 * *$ & 2.80 & 2.06 & 1.81 & 1.81 & 1.69 & 1.45 & 0.09 & 0.08 & 0.06 & 0.05 & 0.05 & 0.05 & 0.04 \\
\hline
\end{tabular}

\begin{tabular}{|c|c|c|c|c|c|c|c|c|c|c|c|c|c|c|}
\hline$J$ & \multicolumn{7}{|c|}{ Annualized mean return (\%) } & \multicolumn{7}{|c|}{ Annualized Sharpe ratio } \\
\hline 1 & $9.38 * * *$ & $7.57^{* * *}$ & $4.66^{* * *}$ & $4.53 * * *$ & $3.91 * * *$ & $2.30 * * *$ & $2.18^{* * *}$ & 0.36 & 0.34 & 0.36 & 0.37 & 0.35 & 0.35 & 0.37 \\
\hline 3 & $9.9 * * *$ & $6.55^{* * *}$ & $5.28 * * *$ & $5.41 * * *$ & $4.28 * * *$ & $2.43^{* * *}$ & $2.43^{* * *}$ & 0.27 & 0.24 & 0.28 & 0.31 & 0.29 & 0.30 & 0.33 \\
\hline 9 & $10.16^{* * *}$ & $9.25^{* * *}$ & $7.06^{* * *}$ & $5.16^{* * *}$ & $3.54 * *$ & $3.17 * *$ & $3.29 * * *$ & 0.27 & 0.26 & 0.23 & 0.20 & 0.19 & 0.24 & 0.26 \\
\hline 12 & $9.25 * * *$ & $7.06 * *$ & $4.78^{* *}$ & 3.54 & 2.55 & $3.04 * *$ & $3.04 * * *$ & 0.24 & 0.21 & 0.18 & 0.16 & 0.16 & 0.22 & 0.23 \\
\hline 24 & 2.92 & 2.06 & 1.57 & 1.33 & 1.81 & 3.04 & 2.92 & 0.13 & 0.12 & 0.11 & 0.12 & 0.14 & 0.18 & 0.18 \\
\hline 36 & 6.04 & 5.54 & 4.41 & 4.28 & 4.28 & 4.16 & 3.66 & 0.23 & 0.21 & 0.19 & 0.20 & 0.20 & 0.20 & 0.18 \\
\hline
\end{tabular}


Table V: Performance of the Diversified 12-1 Time-Series Momentum Strategy-1

The table presents the beta coefficients and their respective $t$-statistics from regressing the equally weighted average across instruments return of the single diversified 12-1 time-series momentum strategy on (i) the monthly MSCI World Index return, (ii) the monthly S\&P GSCI Index return, and (iii) the SMB, HML and UMD which denote the Fama-French factors representing size, value and momentum across U.S. stocks. The sample covers the period from January 1970 through August 2015.

\begin{tabular}{|c|c|c|c|c|c|c|c|}
\hline \multicolumn{8}{|c|}{ Panel A: All Assets } \\
\hline \multirow{3}{*}{$\begin{array}{l}\text { Coefficient } \\
\text { (t-statistic) }\end{array}$} & Intercept & MSCI & GSCI & SMB & HML & UMD & $\mathrm{R}^{2}$ \\
\hline & $0.29 \%$ & 0.04 & -0.01 & 0.02 & 0.05 & 0.30 & $20.78 \%$ \\
\hline & $(2.52)$ & $(1.52)$ & $(-0.77)$ & $(0.66)$ & $(1.14)$ & (11.65) & \\
\hline \multicolumn{8}{|c|}{ Panel B: Equity Index (All) } \\
\hline \multirow{5}{*}{$\begin{array}{l}\text { Coefficient } \\
\text { (t-statistic) }\end{array}$} & Intercept & MSCI & GSCI & SMB & HML & UMD & $\mathrm{R}^{2}$ \\
\hline & $0.23 \%$ & 0.08 & -0.05 & 0.03 & 0.08 & 0.39 & $19.95 \%$ \\
\hline & (1.54) & $(2.21)$ & $(-1.98)$ & $(0.62)$ & $(1.53)$ & $(11.41)$ & \\
\hline & \multicolumn{7}{|c|}{ Developed Markets } \\
\hline & Intercept & "MSCI & "GSCI & SMB & "HML & "UMD & $\overline{\mathrm{R}^{2}}$ \\
\hline \multirow{4}{*}{$\begin{array}{l}\text { Coefficient } \\
(t \text {-statistic) } \\
\end{array}$} & $0.20 \%$ & 0.08 & -0.07 & 0.05 & 0.04 & 0.36 & $17.15 \%$ \\
\hline & (1.26) & $(2.27)$ & $(-2.63)$ & $(1.10)$ & $(0.78)$ & (10.18) & \\
\hline & \multicolumn{7}{|c|}{ Emerging Markets } \\
\hline & Intercept & "MSCI & $\begin{array}{l}\text { GSCI } \\
\end{array}$ & SMB & $\begin{array}{l}\text { HML } \\
\end{array}$ & "UMD & $\overline{\mathrm{R}^{2}}$ \\
\hline Coefficient & $0.30 \%$ & -0.01 & -0.06 & -0.04 & 0.12 & 0.46 & $21.23 \%$ \\
\hline ( $t$-statistic) & & & & $(-0.53)$ & & & \\
\hline \multicolumn{8}{|c|}{ Panel C: Commodity Index } \\
\hline \multirow{3}{*}{$\begin{array}{l}\text { Coefficient } \\
\text { (t-statistic) }\end{array}$} & Intercept & MSCI & GSCI & SMB & HML & UMD & $\mathrm{R}^{2}$ \\
\hline & $0.44 \%$ & -0.03 & 0.10 & 0.01 & -0.05 & 0.12 & $7.04 \%$ \\
\hline & (3.09) & $(-0.85)$ & $(4.19)$ & $(0.18)$ & $(-1.02)$ & (3.88) & \\
\hline
\end{tabular}


Table VI: Performance of the Diversified 12-1 Time-Series Momentum Strategy-2

The table presents the beta coefficients and their respective $t$-statistics from regressing the equally weighted average across instruments return of the single diversified 12-1 time-series momentum strategy on (i) the monthly MSCI World Index return, (ii) the monthly S\&P GSCI Index return, and (iii) the VAL and MOM which denote the "momentum everywhere" factors reported by Asness, Moskowitz and Pedersen (2013), and represent the value and momentum across markets and asset classes. The factors are adjusted to account only for equity and commodity indices. The sample covers the period from January 1970 through August 2015.

\begin{tabular}{|c|c|c|c|c|c|c|}
\hline \multicolumn{7}{|c|}{ Panel A: All Assets } \\
\hline & Intercept & MSCI & GSCI & VAL & MOM & $\mathrm{R}^{2}$ \\
\hline Coefficient & $0.37 \%$ & -0.01 & -0.01 & 0.00 & 0.23 & $15.04 \%$ \\
\hline (t-statistic) & (3.13) & $(-0.33)$ & $(-0.41)$ & $(-0.11)$ & $(8.08)$ & \\
\hline \multicolumn{7}{|c|}{ Panel B: Equity Index (All) } \\
\hline \multirow{5}{*}{$\begin{array}{l}\text { Coefficient } \\
(t \text {-statistic) }\end{array}$} & Intercept & MSCI & GSCI & VAL & MOM & $\mathrm{R}^{2}$ \\
\hline & $0.27 \%$ & 0.05 & -0.05 & -0.08 & 0.50 & $21.09 \%$ \\
\hline & $(1.64)$ & $(1.36)$ & $(-1.53)$ & $(-1.13)$ & $(9.20)$ & \\
\hline & \multicolumn{6}{|c|}{ Developed Markets } \\
\hline & Intercept & "MSCI & GSCI & VAL & MOM & $\overline{\mathrm{R}^{2}}$ \\
\hline \multirow{4}{*}{$\begin{array}{l}\text { Coefficient } \\
(t \text {-statistic) }\end{array}$} & $0.14 \%$ & 0.08 & -0.08 & -0.04 & 0.54 & $24.03 \%$ \\
\hline & $(0.88)$ & $(2.08)$ & $(-2.66)$ & $(-0.67)$ & $(10.11)$ & \\
\hline & \multicolumn{6}{|c|}{ Emerging Markets } \\
\hline & Intercept & "MSCI & "GSCI & VAL & "MOM & $\overline{\mathrm{R}^{2}}$ \\
\hline Coefficient & $-44.00 \%$ & $(-0.12)$ & $(-0.01)$ & $(-0.10)$ & $(0.460$ & $11.90 \%$ \\
\hline ( $t$-statistic) & (1.61) & $(-1.85)$ & $(-0.27)$ & $(-0.82)$ & $(4.61)$ & \\
\hline \multicolumn{7}{|c|}{ Panel C: Commodity Index } \\
\hline & Intercept & MSCI & GSCI & VAL & MOM & $\mathrm{R}^{2}$ \\
\hline Coefficient & $0.25 \%$ & -0.03 & 0.06 & -0.01 & 0.31 & $38.97 \%$ \\
\hline (t-statistic) & $(2.13)$ & $(-1.10)$ & (3.02) & $(-0.44)$ & (15.09) & \\
\hline
\end{tabular}


Table VII: Time-Series Momentum and Mutual Fund Performance

The table reports the alpha and beta coefficients from regressing returns of mutual funds (developed, emerging, and commodity funds) on the single diversified 12-1 time-series momentum strategy (TSMOM), the 12-1 longonly time-series momentum strategy (Long Only) and a number of control variables MSCI, GSCI, VAL and MOM. The numbers in parentheses are the Newey-West adjusted $t$-values from the specified regressions. The sample covers the period starting from February 1971 for developed funds, October 1989 for emerging funds, and April 1997 for commodity funds, through August 2015.

\begin{tabular}{|c|c|c|c|c|c|c|c|c|c|c|c|c|c|}
\hline \multicolumn{7}{|c|}{ Panel A: International Equity Funds (Developed Markets) } & & & & & & & \\
\hline \multicolumn{7}{|c|}{ International Developed Equity Market Funds - TSMOM } & \multicolumn{7}{|c|}{ International Developed Equity Market Funds - Long Only } \\
\hline Intercept & TSMOM & MSCI & GSCI & VAL & MOM & $\mathrm{R}^{2}$ & Intercept & Long Only & MSCI & GSCI & VAL & MOM & $\mathrm{R}^{2}$ \\
\hline $1.01 \%$ & -0.05 & & & & & $0.20 \%$ & $0.14 \%$ & 1.05 & & & & & $47.45 \%$ \\
\hline$(4.81)$ & $(-0.33)$ & & & & & & $(0.94)$ & $(21.94)$ & & & & & \\
\hline $0.40 \%$ & 0.02 & 0.90 & 0.03 & 0.09 & 0.07 & $88.45 \%$ & $0.38 \%$ & 0.12 & 0.84 & 0.04 & 0.08 & 0.03 & $88.75 \%$ \\
\hline$(5.42)$ & $(0.63)$ & $(46.95)$ & $(2.91)$ & $(2.67)$ & $(2.15)$ & & $(5.30)$ & $(2.22)$ & $(23.26)$ & $(3.03)$ & $(2.45)$ & $(1.15)$ & \\
\hline \multicolumn{14}{|c|}{ Panel B: International Equity Funds (Emerging Markets) } \\
\hline \multicolumn{7}{|c|}{ International Emerging Equity Market Funds - TSMOM } & \multicolumn{7}{|c|}{ International Emerging Equity Market Funds - Long Only } \\
\hline Intercept & TSMOM & MSCI & GSCI & VAL & $\mathrm{MOM}$ & $\mathrm{R}^{2}$ & Intercept & Long Only & MSCI & GSCI & VAL & MOM & $\mathrm{R}^{2}$ \\
\hline $0.01 \%$ & -0.26 & & & & & $4.72 \%$ & $-0.07 \%$ & 1.20 & & & & & $49.04 \%$ \\
\hline (2.66) & $(-1.69)$ & & & & & & $(-0.23)$ & (14.95) & & & & & \\
\hline $0.22 \%$ & 0.01 & 1.07 & 0.07 & 0.51 & 0.25 & $68.20 \%$ & $-0.03 \%$ & 0.68 & 0.78 & 0.08 & 0.36 & 0.01 & $79.19 \%$ \\
\hline$(0.91)$ & $(0.18)$ & (20.76) & $(2.45)$ & $(5.42)$ & $(3.24)$ & & $(-0.14)$ & $(11.47)$ & (12.54) & $(2.76)$ & $(4.50)$ & $(0.21)$ & \\
\hline \multicolumn{14}{|c|}{ Panel C: Commodity Funds } \\
\hline \multicolumn{7}{|c|}{ CommodityFunds - TSMOM } & \multicolumn{7}{|c|}{ Commodity Funds - Long Only } \\
\hline Intercept & TSMOM & MSCI & GSCI & VAL & MOM & $\mathrm{R}^{2}$ & Intercept & Long Only & MSCI & GSCI & VAL & MOM & $\mathrm{R}^{2}$ \\
\hline $0.27 \%$ & 0.01 & & & & & $0.00 \%$ & $-0.03 \%$ & 1.58 & & & & & $53.88 \%$ \\
\hline$(0.63)$ & $(0.04)$ & & & & & & $(-0.09)$ & (11.67) & & & & & \\
\hline $0.47 \%$ & -0.02 & 0.05 & 0.72 & -0.06 & -0.02 & $87.07 \%$ & $0.43 \%$ & 0.48 & 0.03 & 0.61 & -0.08 & -0.13 & $88.80 \%$ \\
\hline (3.30) & $(-0.29)$ & (1.85) & (18.27) & $(-1.50)$ & $(-0.40)$ & & (3.52) & $(4.76)$ & $(0.92)$ & (11.09) & $(-2.07)$ & $(-3.23)$ & \\
\hline
\end{tabular}


Table VIII: Quantitative Easing and Correlations among Conventional Asset Classes

The table reports correlations across the equity indexes of G7 countries, the BRIC countries, and the broad commodity index during 3 different time periods: pre-QE (January 1970-November 2008), at-QE (December 2008-October 2014), and post-QE (November 2014-August 2015).

\begin{tabular}{|c|c|c|c|c|c|c|c|c|c|c|c|c|}
\hline & Canada & France & Germany & Italy & Japan & UK & USA & Russia & Brazil & India & China & S\&P GSCI \\
\hline Canada & 1.00 & & & & & & & & & & & \\
\hline France & 0.52 & 1.00 & & & & & & & & & & \\
\hline Germany & 0.47 & 0.70 & 1.00 & & & & & & & & & \\
\hline Italy & 0.40 & 0.53 & 0.50 & 1.00 & & & & & & & & \\
\hline Japan & 0.36 & 0.42 & 0.39 & 0.38 & 1.00 & & & & & & & \\
\hline UK & 0.56 & 0.60 & 0.52 & 0.42 & 0.40 & 1.00 & & & & & & \\
\hline USA & 0.74 & 0.54 & 0.52 & 0.35 & 0.34 & 0.57 & 1.00 & & & & & \\
\hline Russia & 0.58 & 0.41 & 0.37 & 0.36 & 0.38 & 0.48 & 0.48 & 1.00 & & & & \\
\hline Brazil & 0.38 & 0.33 & 0.31 & 0.26 & 0.32 & 0.34 & 0.38 & 0.57 & 1.00 & & & \\
\hline India & 0.46 & 0.43 & 0.41 & 0.40 & 0.31 & 0.37 & 0.39 & 0.33 & 0.45 & 1.00 & & \\
\hline China & 0.54 & 0.37 & 0.39 & 0.19 & 0.23 & 0.44 & 0.47 & 0.40 & 0.46 & 0.39 & 1.00 & \\
\hline S\&P GSCI & 0.27 & 0.13 & 0.04 & 0.09 & 0.11 & 0.05 & 0.04 & 0.18 & 0.12 & 0.29 & 0.23 & 1.00 \\
\hline \multicolumn{13}{|c|}{ Panel B: At-QE Period } \\
\hline & Canada & France & Germany & Italy & Japan & UK & USA & Russia & Brazil & India & China & S\&P GSCI \\
\hline Canada & 1.00 & & & & & & & & & & & \\
\hline France & 0.76 & 1.00 & & & & & & & & & & \\
\hline Germany & 0.75 & 0.94 & 1.00 & & & & & & & & & \\
\hline Italy & 0.70 & 0.94 & 0.88 & 1.00 & & & & & & & & \\
\hline Japan & 0.54 & 0.61 & 0.65 & 0.58 & 1.00 & & & & & & & \\
\hline UK & 0.85 & 0.89 & 0.86 & 0.86 & 0.65 & 1.00 & & & & & & \\
\hline USA & 0.83 & 0.86 & 0.87 & 0.77 & 0.65 & 0.86 & 1.00 & & & & & \\
\hline Russia & 0.80 & 0.72 & 0.74 & 0.68 & 0.53 & 0.77 & 0.70 & 1.00 & & & & \\
\hline Brazil & 0.83 & 0.69 & 0.65 & 0.64 & 0.44 & 0.73 & 0.67 & 0.75 & 1.00 & & & \\
\hline India & 0.71 & 0.63 & 0.67 & 0.63 & 0.54 & 0.63 & 0.62 & 0.68 & 0.74 & 1.00 & & \\
\hline China & 0.72 & 0.67 & 0.72 & 0.61 & 0.45 & 0.69 & 0.65 & 0.68 & 0.75 & 0.69 & 1.00 & \\
\hline S\&P GSCI & 0.72 & 0.59 & 0.55 & 0.53 & 0.34 & 0.71 & 0.63 & 0.68 & 0.54 & 0.42 & 0.51 & 1.00 \\
\hline
\end{tabular}


Panel C: Post-QE Period

\begin{tabular}{|c|c|c|c|c|c|c|c|c|c|c|c|c|}
\hline & Canada & France & Germany & Italy & Japan & UK & USA & Russia & Brazil & India & China & S\&P GSCI \\
\hline Canada & 1.00 & & & & & & & & & & & \\
\hline France & 0.62 & 1.00 & & & & & & & & & & \\
\hline Germany & 0.43 & 0.87 & 1.00 & & & & & & & & & \\
\hline Italy & 0.56 & 0.91 & 0.73 & 1.00 & & & & & & & & \\
\hline Japan & 0.59 & 0.81 & 0.71 & 0.82 & 1.00 & & & & & & & \\
\hline UK & 0.74 & 0.88 & 0.62 & 0.80 & 0.82 & 1.00 & & & & & & \\
\hline USA & 0.70 & 0.78 & 0.73 & 0.71 & 0.77 & 0.82 & 1.00 & & & & & \\
\hline Russia & 0.58 & 0.60 & 0.38 & 0.80 & 0.65 & 0.57 & 0.33 & 1.00 & & & & \\
\hline Brazil & 0.75 & 0.54 & 0.32 & 0.49 & 0.53 & 0.66 & 0.35 & 0.69 & 1.00 & & & \\
\hline India & -0.22 & 0.45 & 0.58 & 0.44 & 0.50 & 0.33 & 0.38 & 0.12 & -0.01 & 1.00 & & \\
\hline China & 0.65 & 0.44 & 0.35 & 0.32 & 0.67 & 0.57 & 0.37 & 0.44 & 0.67 & -0.05 & 1.00 & \\
\hline S\&P GSCI & 0.55 & 0.18 & -0.10 & 0.41 & 0.31 & 0.35 & 0.06 & 0.83 & 0.70 & -0.23 & 0.40 & 1.00 \\
\hline
\end{tabular}


Table IX: Time-Series Momentum and Quantitative Easing, Regression Analysis

The table presents the beta coefficients and their respective $t$-statistics from regressing the equally weighted average across instruments return of the single diversified 12-1 time-series momentum strategy on (i) the monthly MSCI World Index return, (ii) the monthly S\&P GSCI Index return, (iii) the VAL and MOM which denote the "momentum everywhere" factors reported by Asness, Moskowitz and Pedersen (2013), and represent the value and momentum across markets and asset classes, and (iv) QE which represents a dummy variable that takes the value of 1 in cases where the Federal Reserve stimulated the economy through quantitative easing. The factors are adjusted to account only for equity and commodity indices. DEV stands for developed markets equity indexes, and $E M$ stands for emerging market equity indexes. The sample covers the period from January 1970 through August 2015.

\begin{tabular}{lccccccc}
\hline \multicolumn{7}{c}{ Independent Variable } \\
\hline & MSCI & GSCI & VAL & MOM & QE & Intercept & $\mathrm{R}^{2}$ \\
\hline Dependent Variable & & & & & & & \\
\hline TSMOM ALL & -0.01 & -0.01 & -0.01 & 0.22 & -0.01 & $0.51 \%$ & $16.32 \%$ \\
& $(-0.23)$ & $(-0.52)$ & $(-0.33)$ & $(7.86)$ & $(-2.82)$ & $(3.98)$ & \\
\hline TSMOM EQ & 0.01 & -0.03 & -0.00 & 0.15 & -0.01 & $0.63 \%$ & $5.75 \%$ \\
& -0.21 & $(-1.17)$ & $(-0.05)$ & $(3.95)$ & $(-2.78)$ & $(3.55)$ & \\
\hline- DEV & 0.03 & -0.05 & 0.01 & 0.17 & -0.02 & 0.54 & $5.10 \%$ \\
& $(0.70)$ & $(-1.93)$ & $(0.29)$ & $(4.14)$ & $(-2.72)$ & $(3.01)$ & \\
- EM & -0.37 & 0.41 & 0.16 & 0.34 & -0.07 & $6.83 \%$ & $6.26 \%$ \\
& $(-1.83)$ & $(2.74)$ & $(0.48)$ & $(1.12)$ & $(-3.49)$ & $(6.71)$ & \\
\hline TSMOM COM & -0.02 & 0.08 & -0.03 & 0.37 & -0.00 & $0.30 \%$ & $34.56 \%$ \\
& $(-0.83)$ & $(3.72)$ & $(-1.03)$ & $(12.66)$ & $(-0.77)$ & $(2.23)$ & \\
\hline
\end{tabular}

